\title{
العنف الأسري الموجه نهو فتيات الجامعة وعلاقته باتخاذ القرار
}

\author{
إعلداد \\ د. نوره عبدالرحمب أهمد الشايع \\ م/ حصة عبد الرهم. السميط \\ أستاذ التدريب قسم الاقتصاد المنزلي \\ كلية التربية الأساسية
}

مجلة بحوث التربية النوعية ـ جامعة المنصورة

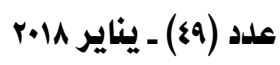




\title{
العنف الأسري الموجه نهو فتيات الجاهعة وعلاقته باتخاذ القرار
}

\author{
إعداد \\ د · نورهعبدالرحم:أحمد الشايع \\ د/حصة حبد الرحمنالسمبط
}

مقدهمة : مقدم

الإنسان الكويتي يقع ِِّ بؤرة الاهتمام الأولى من الدولة لأنه بمثابة الثروة الأساسية لها بل

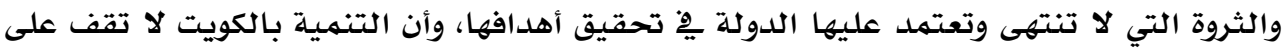
التنمية الاقتصادية وزيادة الدخل وحدها بل تعدت ذلك إلى الماتلى المفهوم الأشمل من خلال تنمية

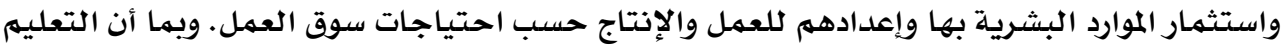

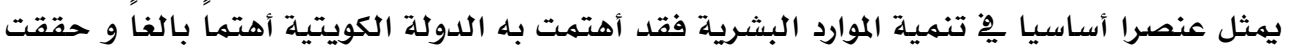

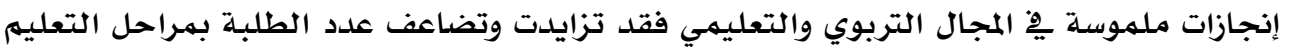

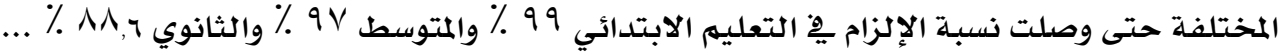

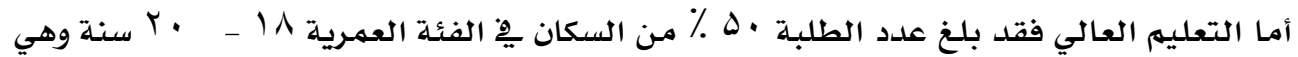

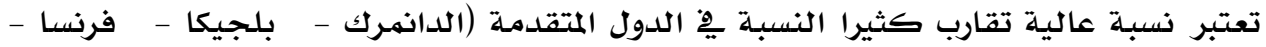

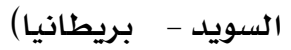

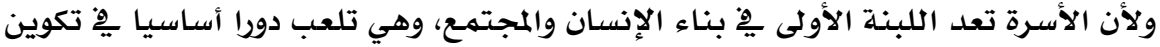

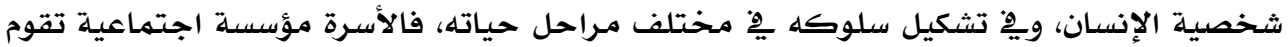

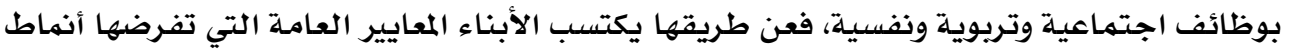

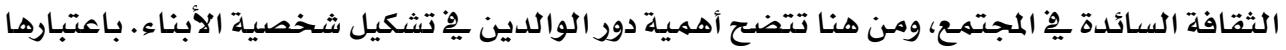

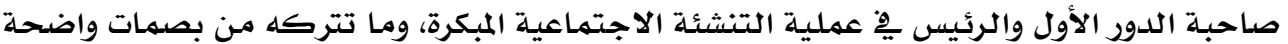

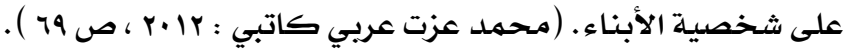

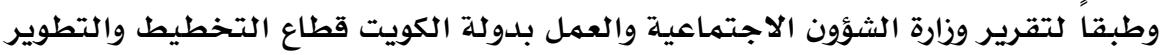

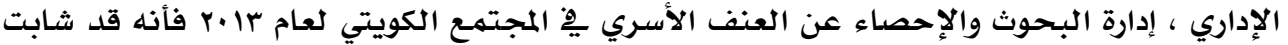

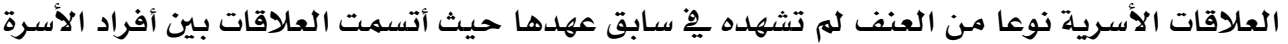

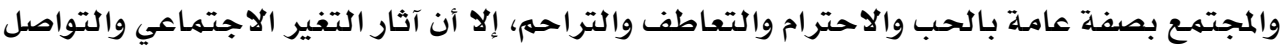

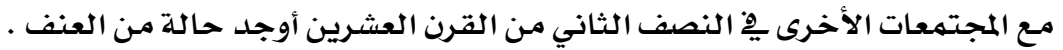
وعلى الرغم مـن أن العنف الأسري الموجه نحو الأبناء قديم قدم التاريخ إلا أنه له يحظ

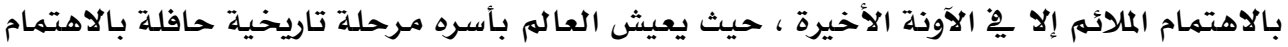


العالمي على صعيد الدول والشعوب وعقدت العديد من المؤتمرات الدولية والتي تعنى بدراسة هذه

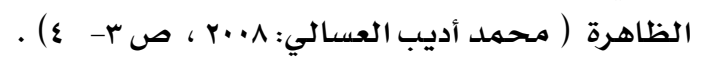

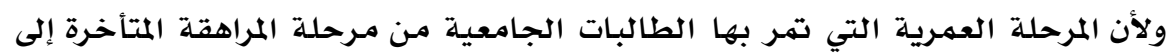

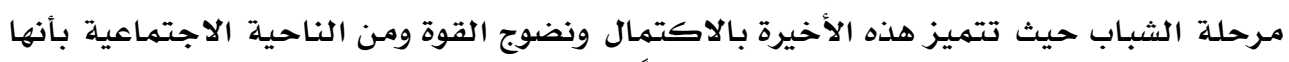

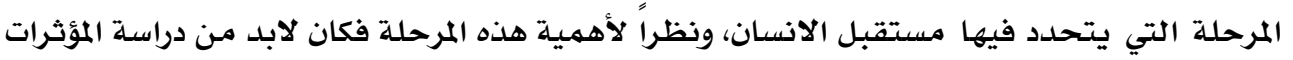

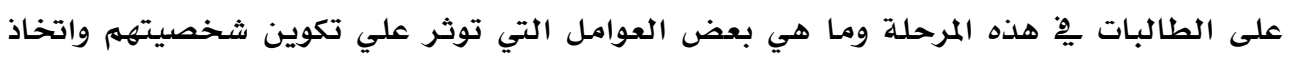
قرارتهن.

ولأهمية اتخاذ القرارات عند الطلبة تسعى الجامعات الكويتية إلى إكساب الطلبة المهارات

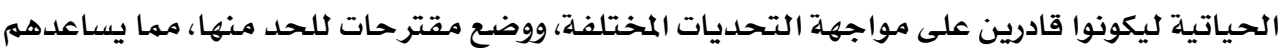

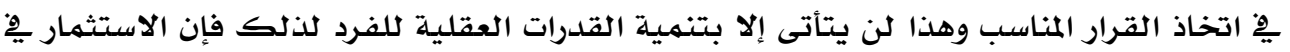

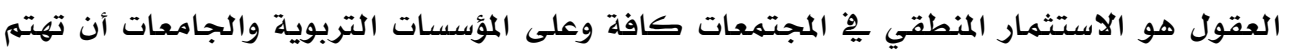

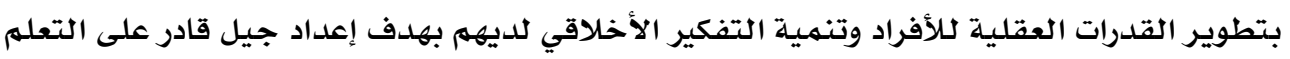

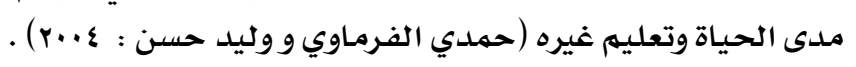

وترى الباحثة أن العنف الأسري تجاه فتيات الجامعة له أثاره السلبية على شخصيتهن

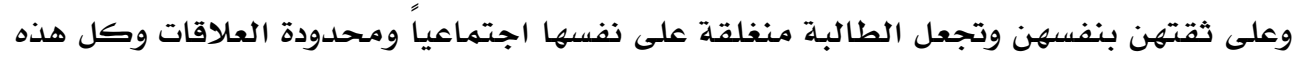

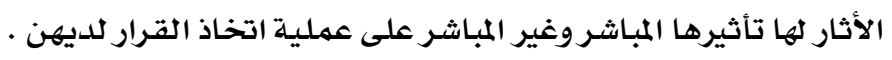

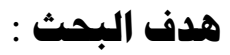

يهدف البحثث إلي التعرف على العلاقة بين إساءة المعاملة الوالدية ( العنف الأسرى ) وأتخاذ

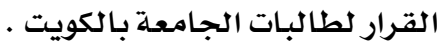

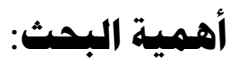

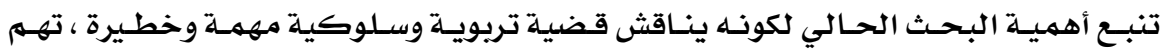

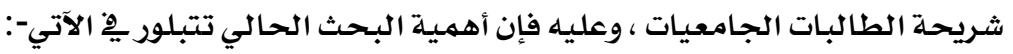

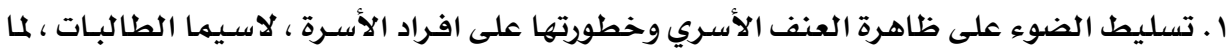

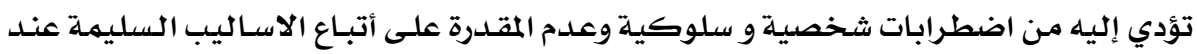

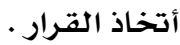

r. توعية الأهل بضرورة الابتعاد عن ممارسة العنف داخل الأسرة ، ومحاولة حل مشكلات الأسرة

بطرق تربوية وهادئة بعيدا عن الأبناء.

r. توضيح أهمية أتباع الطرق العلمية السليمة عنداءئد أتخاء أتخاذ القرارات ولا سيما المصيرية . 
ا. الحدود الموضوعية: اقتصر موضوع الدراسة الحالية على موضوعي العنف الأسري ، اتخاذ

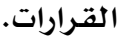

r . الحدود المكانية: اقتصر البحث على عينة من طالبات الجامعة بدولة الكويت .

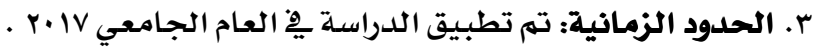

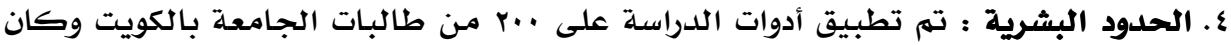

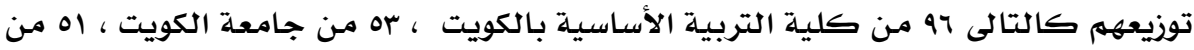

. American College of Middle East

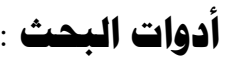

I ـ مقياس العنف الأسري دل نور جبار علي (r. r ) .

وقد طبق هذا الاستبيان على عينـة كبيرة مـن الطالبـات لتحديد الطالبـات لتحديديـ مـا اذا

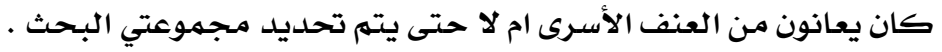

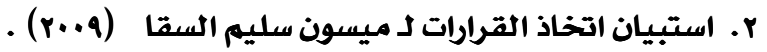

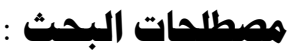

العنف الأسري :

يعرف العنف الأسري بأنه: "يشير إلى الأفعال المباشرة وغير المباشرة التي توجها نحو أحد الدا

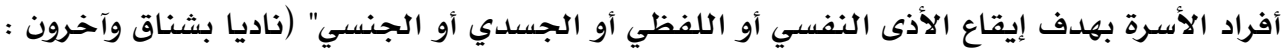

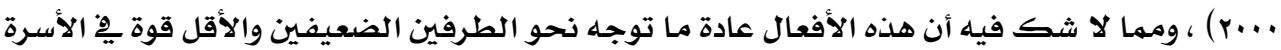

وهما : المرأة والطفل.

اتخاذ القرار:

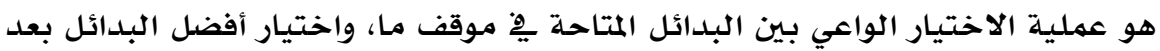

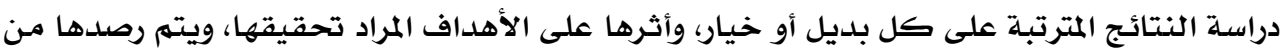

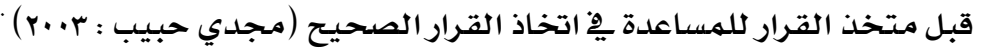

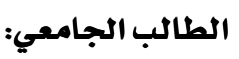

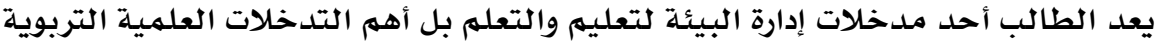

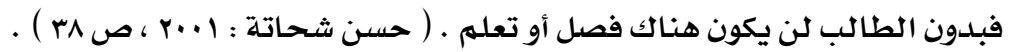

ويعرف أيضا بأنه الشخص الذي سمحت له كفاءته العلمية بالانتقال من المرحلة الثانوية

أو مرحلة التكوين المهني التقني العالي إلى جامعة تبعا لتخصصده الفرعي بواسطة شهادة أو دبلوم

يؤهله لذلك. 
و بالتالي هناك من أعطى تعريف للطالب الجامعي حيث عرفه "رياض قاسهم " بأنه: شخص

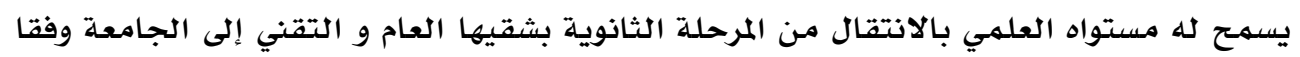

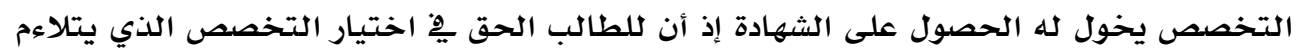

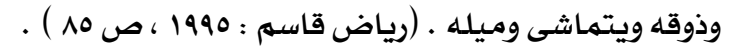

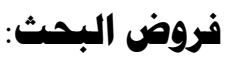

• الفرض الأول: يوجد علاقة ارتباط عكسى ذات دلالة إحصائية بين العنف الأسري وعملية اتخاذ القرارات السليمة . الفرض الفوجل • الفرض الثاني: هناك فروق ذات دلالة إحصائية بين الطالبـات الذين يعانون من العنف الأسرى

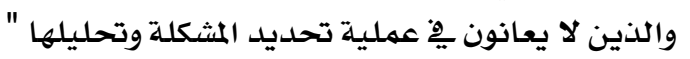
• الفرض الثالث: هناك فروق ذات دلالة إحصائية بين الطالبات الذين يعانون من العنف الأسـرى

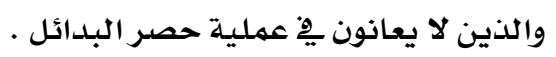
• الفرض الرابع: هناك فروق ذات دلالة إحصائية بين الطالبـات الذين يعـانون مـن العنف الأسـرى لونى والذين لا يعانون يف عملية تقييم البدائل ".

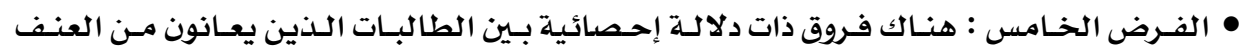

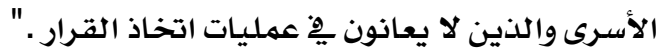

\section{الإطار النظري للبحث :} مفهوم العنف الأسري وتعريفه:

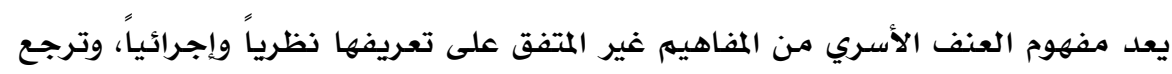

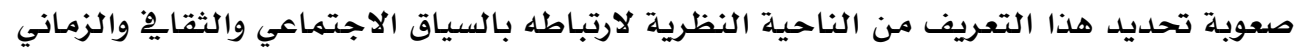

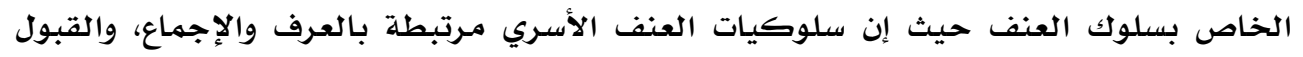

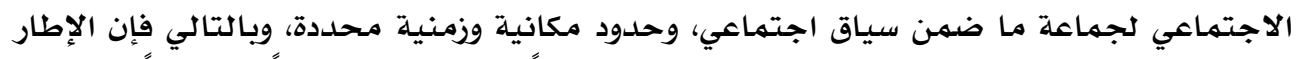

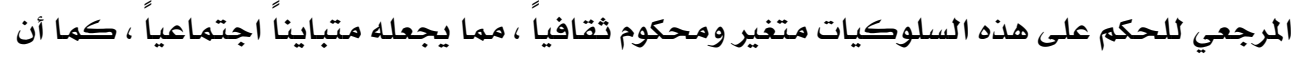

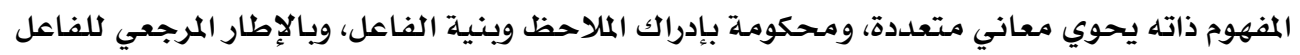

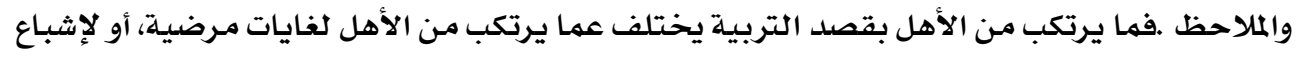

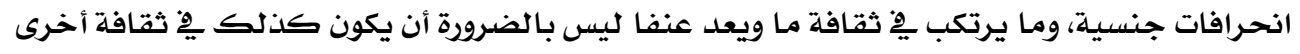

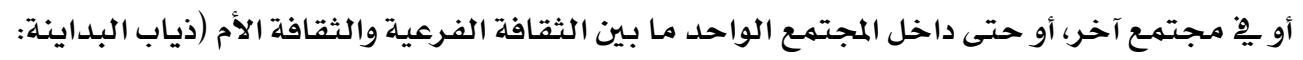

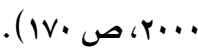

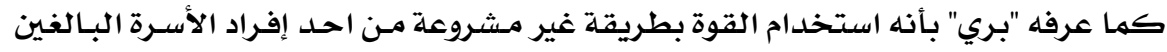
ضد فرد آخر من العائلة، ويعد الأطفال الضحايا المألوفون يِّ البيوت. (Berry, 1995). 
مجلة بحوث التربية النوعية - علد

كما يعرف العنف الأسري بأنه "الاعتداء البـدني أو النفسي الواقـع على الأشـخاص واللذي

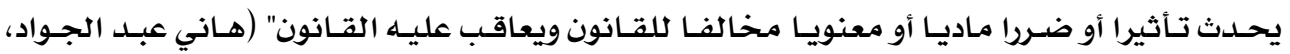

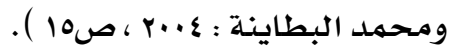

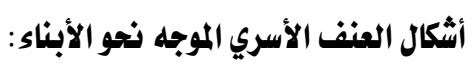

ا. العنف الجسلدي: يعد هذا النوع من الإساءة من أكثر أنواع الإساءة شيوعا، وذلك بسبب الكاءي

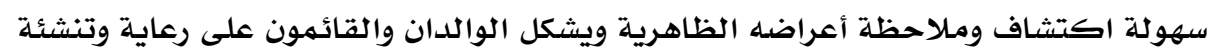

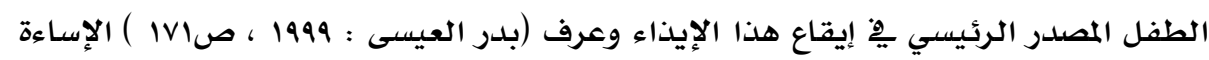

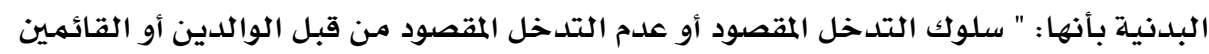

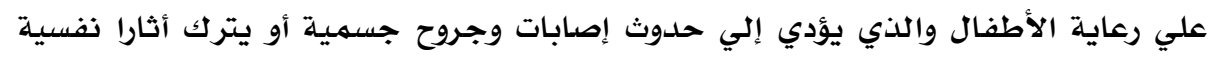
واجتماعيةٍ سيئة علي الأطفال تعوق نموهم النفسي والاجتهماعي وتؤثر علي شخصيتهم تأثيرا

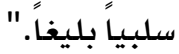
r. العنف النفسي والانفعالي: تتراوح إساءة المعاملة الانفعالية بين رفض الأهل الابتسام ِِّ وجها.

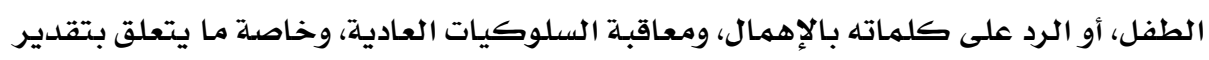

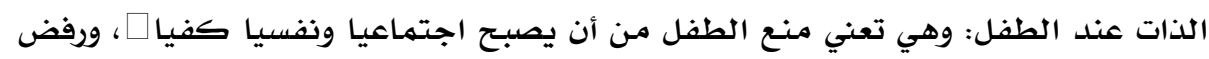

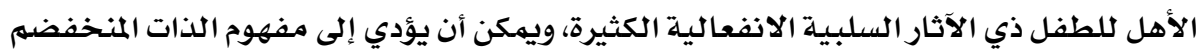
(Garbarino, J., 1980, p. 74-75)

r.الإهمال (Neglect): يعد الإهمال بالنسبة للطفل أكبر مهلدد اجتماعي له وقد يؤدي

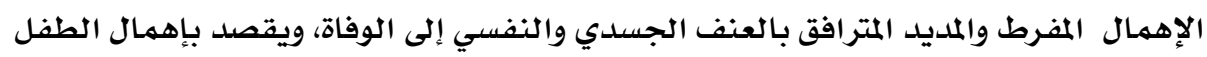

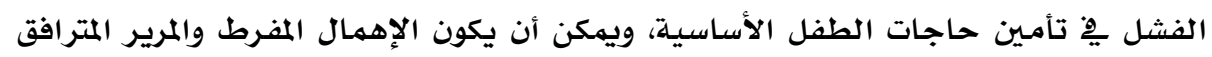

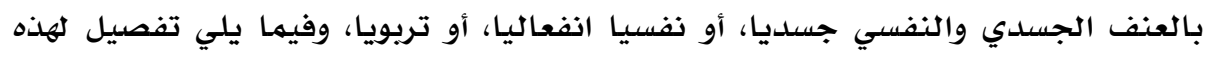

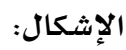

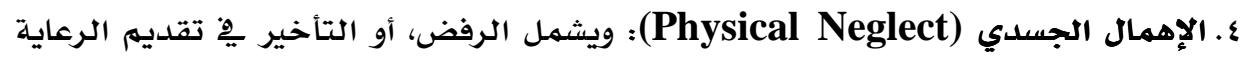

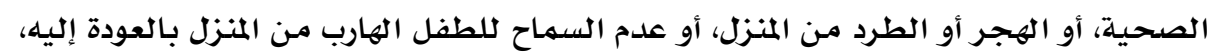

الإهمال التربوي (Educational Neglect): كعدم تسجيل الطفل والإرثاد غير الكايِّ.

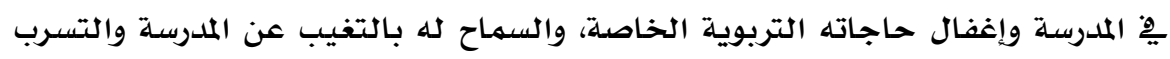
منها.

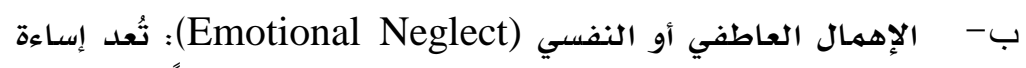

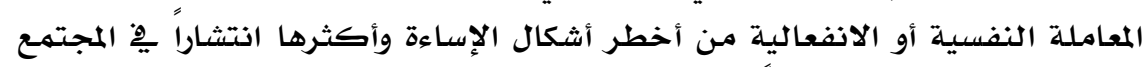

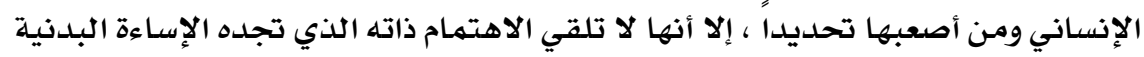

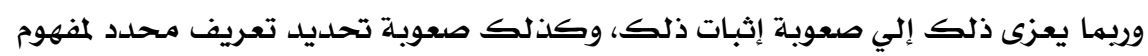

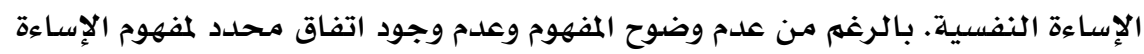


النفسية أو الانفعالية إلا أن هنالك بعض المحاولات لإيجاد تعريف للإساءة النفسية،

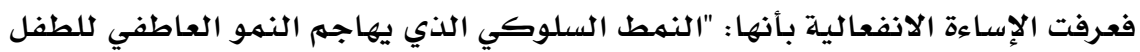

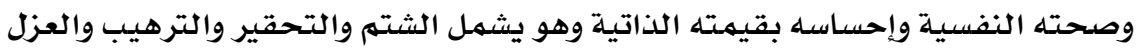

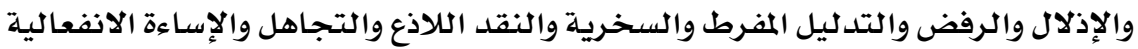

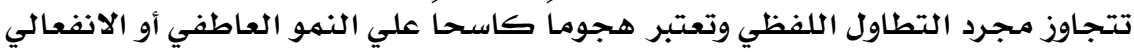

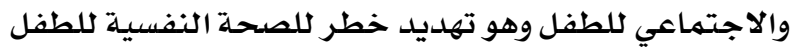

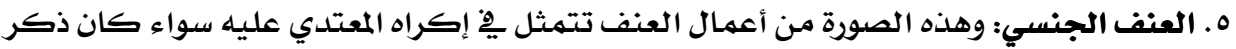

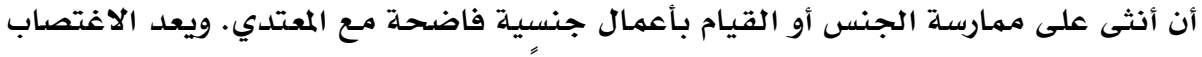

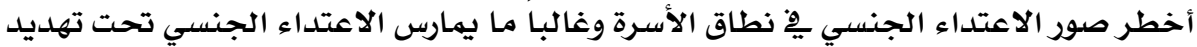

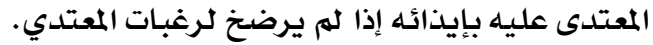

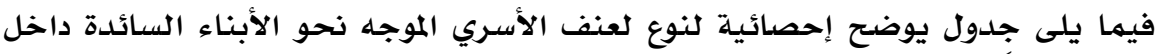

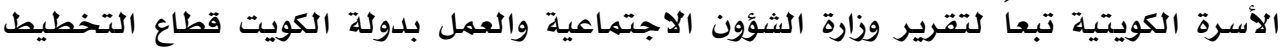

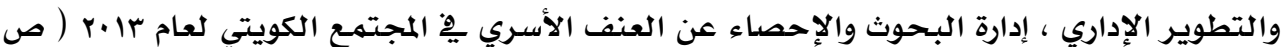

جدول (1) نوع العنف داخل الأسرة الكويتية حسب النوع

\begin{tabular}{|c|c|c|c|c|c|c|}
\hline \multirow{2}{*}{\multicolumn{2}{|c|}{ الجملة }} & \multicolumn{4}{|c|}{ 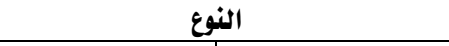 } & \\
\hline & & \multicolumn{2}{|c|}{ أنثى } & \multicolumn{2}{|c|}{ ذكر } & \\
\hline$\%$ & العدد & $\%$ & العلد العد & $\%$ & العلد العد & \\
\hline $9 \xi, 1$ & I\&V7 & 9 १६१ & rYY & $9 r, r$ & $v \leqslant q$ & العنف البلدى \\
\hline $9 \Lambda, \varepsilon$ & $10 \leqslant \xi$ & $9 \Lambda, \varepsilon$ & vos & $9 \Lambda, \varepsilon$ & va. & العنف اللفظى والمعنوى \\
\hline $9 \xi, \wedge$ & $1 \varepsilon \wedge A$ & $१ ६, १$ & rrY & $9 \xi, \wedge$ & VथI & العنف المادى \\
\hline$\wedge 0, \xi$ & Ir. & $\Lambda 0, r$ & 7or & 10,7 & TAV & العنف الجنسى \\
\hline $1 \cdots, \cdot$ & 1079 & $1 \cdots, \cdot$ & V97 & $1 . ., \cdot$ & $\Lambda \cdot r$ & الجملة \\
\hline
\end{tabular}

دوافع العنف الأسري: إن الدوافع التي يندفع الإنسان بمقتضاها نحو العنف الأسري يمكن تقسيمها إلى ما يلي:

ا ـ الدوافع الذاتية: ونعني بهذا النوع من الدوافع تلك الدئ الدوافع التي تنبع من ذات الإنسان، ونفسهه،

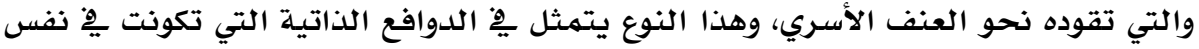

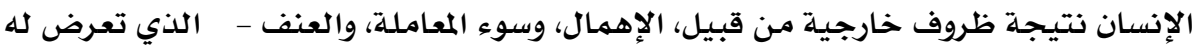

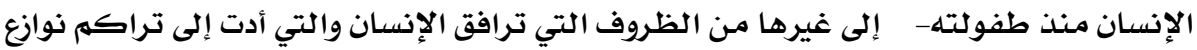

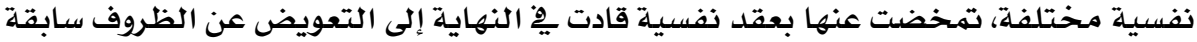

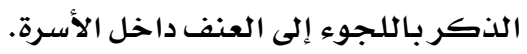


مجلة بحوث التربية النوعية - علد

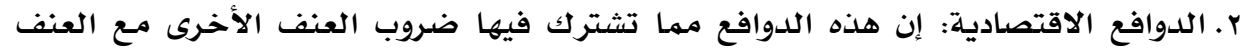

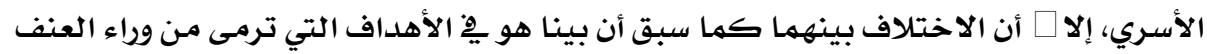

بدافع اقتصادي.

r.الدوافع الاجتماعية: إن هذا النوع من الدوافع يتمثل ِِّ العادات والتقاليد التي اعتادها

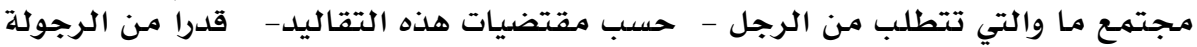

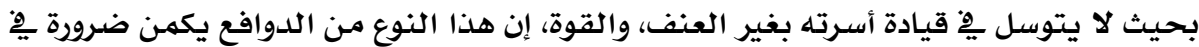

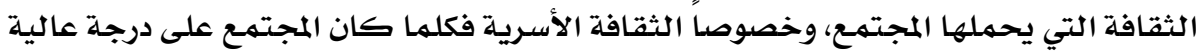

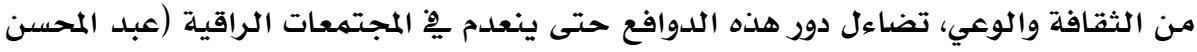

$$
\text { المطيري : ، صع المقافة ). }
$$

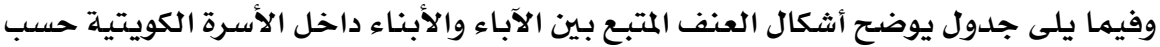

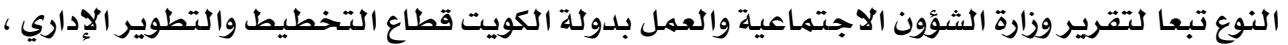

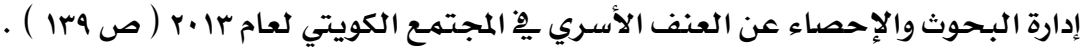
جدول (r) أشكال العنف المتبع بين الآباء والأبناء داخل الأسرة الكويتية حسب النوع .

\begin{tabular}{|c|c|c|c|c|c|c|}
\hline \multirow{2}{*}{\multicolumn{2}{|c|}{ جملة }} & \multicolumn{4}{|c|}{ 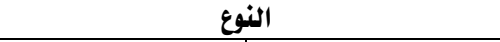 } & \multirow{3}{*}{ أسلوب التعامل المتبع بين الآباء } \\
\hline & & \multicolumn{2}{|c|}{ إناث } & \multicolumn{2}{|c|}{ ذكور } & \\
\hline$\%$ & العلد & $\%$ & العدد & $\%$ & العلد & \\
\hline 9,1 & $10 \varepsilon$ & $1 \cdot, r$ & va & $9, r$ & vo & الضرب المبرح \\
\hline IV,r & rrr & $19, \mathrm{~V}$ & 101 & 10,1 & $|r|$ & السباب والشتائي \\
\hline $17, r$ & roo & $r \cdot, r$ & 100 & Ir,o & $1 .$. & الاستهزاء والإهمال \\
\hline$r r, r$ & r.7 & $r \xi, 0$ & 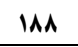 & $r r, r$ & IVA & الحرمان من المصروف \\
\hline IV,, $\mathrm{V}$ & rYA & 19,1 & $10 r$ & $10, \mathrm{r}$ & irq & الحرمان من مشاهدة التلفزيون \\
\hline $\mathrm{rA}, \mathrm{Y}$ & $\leqslant \xi \Lambda$ & $r r, r$ & roo & $r \xi, \cdot$ & 194 & الحرمان من الخروج والنزهة \\
\hline ri, 9 & $0 .$. & $r q, v$ & rAl & $r v, r$ & riq & اللجوي إلى التخويف والتهديلد \\
\hline VY, 7 & Ir.r & $v_{r}, \cdot$ & $\Delta 09$ & $\Lambda \cdot, 1$ & 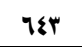 & التفاهم والإقناع \\
\hline$r r, 1$ & llrr & $v, v$ & $0 \leqslant 9$ & Vr, 7 & OAT & التوجيه للصواب \\
\hline $7 r, 7$ & qAr & $0 \wedge, 0$ & $\leqslant \xi \Lambda$ & 79,0 & ors & الموعظة الحسنة \\
\hline$r, r$ & $\xi r$ & 1,1 & $1 \xi$ & $r, q$ & $r q$ & أخرى \\
\hline $1 \cdots, \cdot$ & 1079 & $1 \cdots, \cdot$ & v7y & $1 \cdots, \cdot$ & $\Lambda \cdot r$ & الجملة \\
\hline
\end{tabular}

\section{هفهوم اتخاذ القرار:}

تُعد عملية اتخاذ القرارات جزء من حل المشكلة وهي آلية لاتخاذ البدائل والخيارات يِّ كل

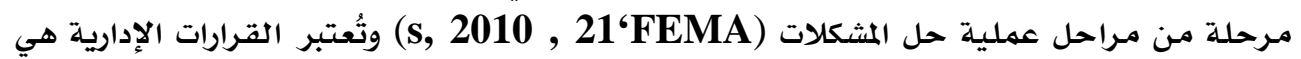


جوهر عمل القيادة الإداريـة، وهي نقطة الانطلاق بالنسبة لجميع النشاطات والتصرفات التي تتم

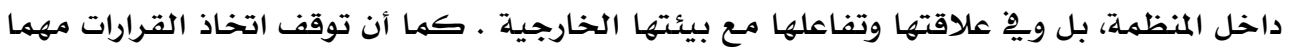

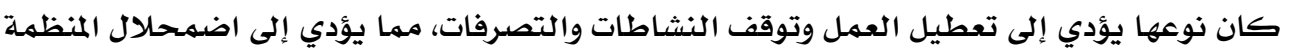

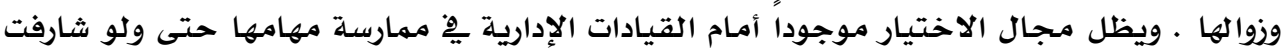

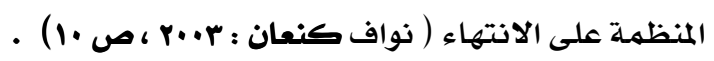
والحياة قرار، والقرار فرصدة، والفرصدة قد لا تتكرر، والناجتح هو من ينتهز الفرصدة ويغتتهها

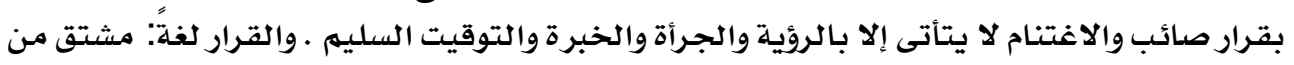

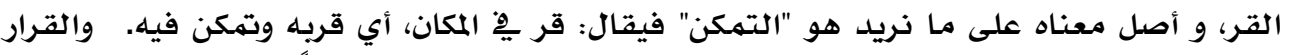

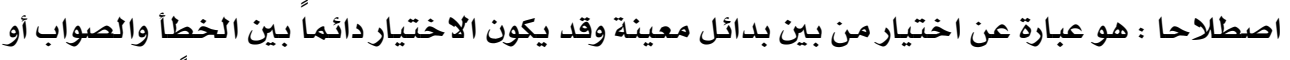

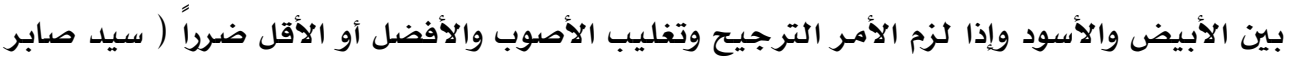

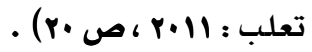

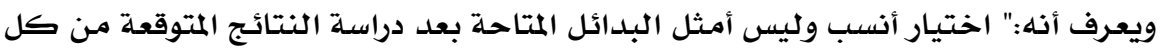

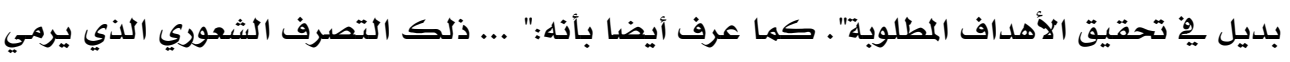

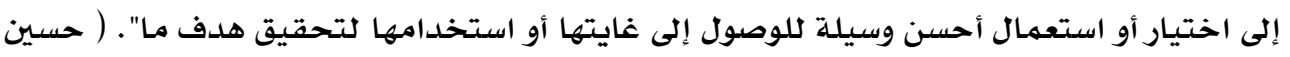

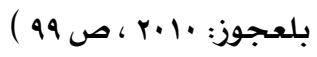
فاتخاذ القرار يعني قيام الفرد بالمفاضلة بين بعض البدائل التي تم اختيارها قي ضواء

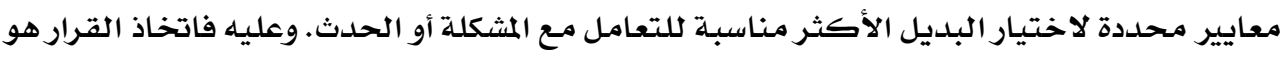

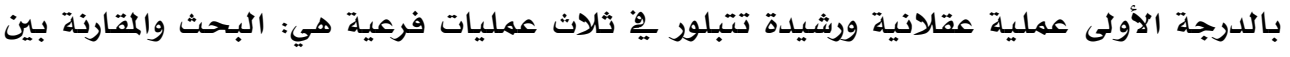

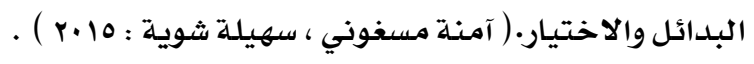
عرفه برنارد على أنه: عملية تقوم على الاختيار المدرك للغايات التي تكون ِِّ الغالب

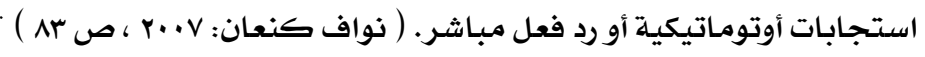

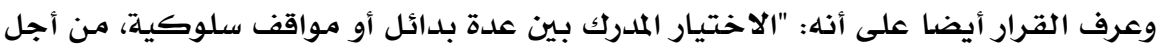

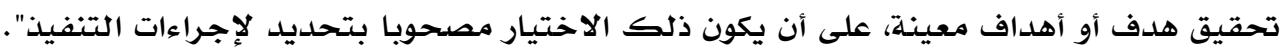

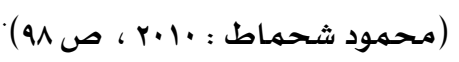
والقرار يعرف أيضا بأنه: الاختيار المدرك بين البدائل المتاحة يِّ موقف معين أو هو عملية

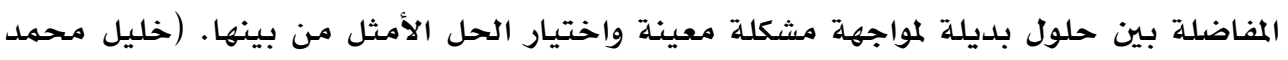

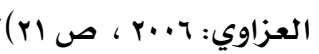

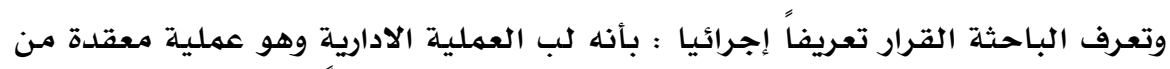

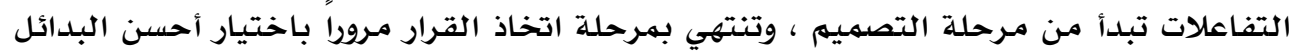

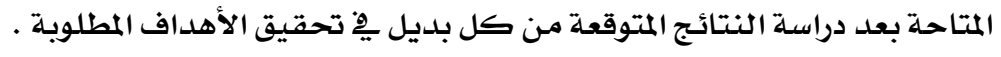




\section{هراحل عملية اتخاذ القرار:}

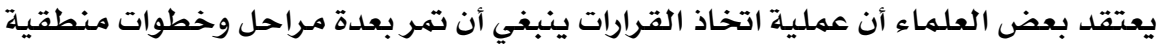

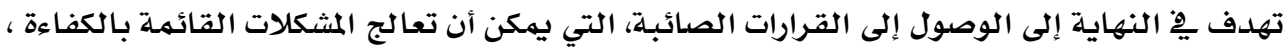

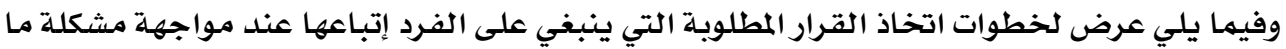

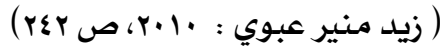

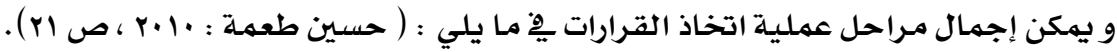
ا- تحديد المشكلة: عند تحديد المشكلة يجب التعمق يِّ دراستها لمعرفة جوهر المشكلة الحقيقي

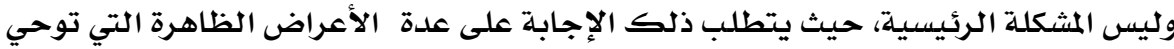

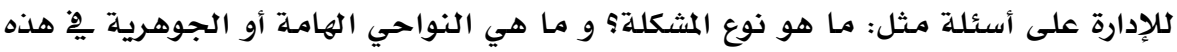

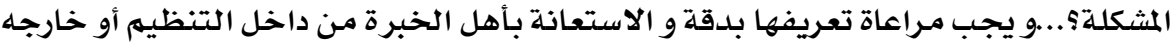

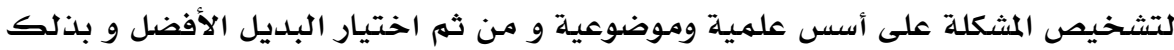
تنجو القرارات الإستراتيجية من احتمالات ألمات الخطأ.

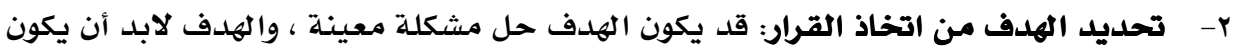

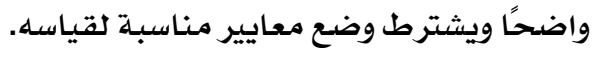

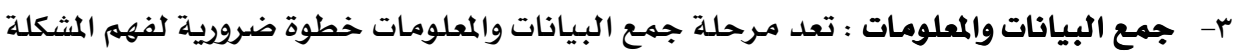

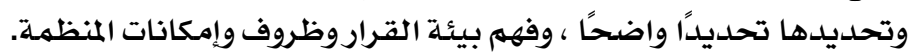

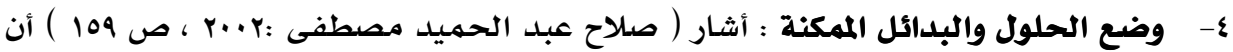

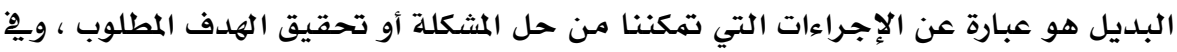

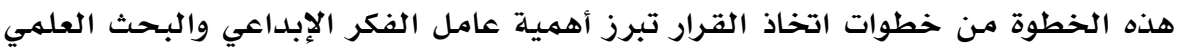
والدراسات المختلفة قبل اتخاذ القرار.

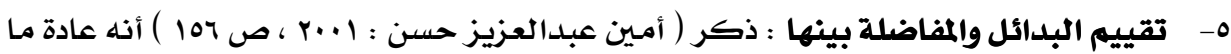

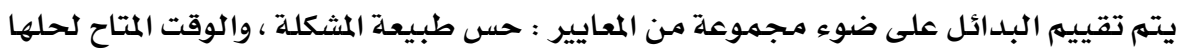

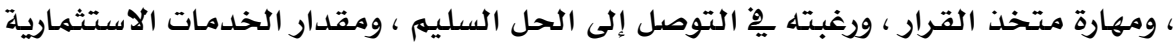

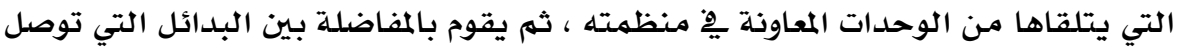

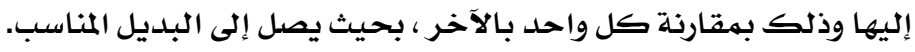

\section{ويْ حال المفاضلة يجب الأخذ بعين الاعتبار النواحي التالية:}

• إمكانية تنفيذ البديل ومدى توفر الإمكانيات المادية و البشرية الملائمسة اللازمـة لتنفيذه.

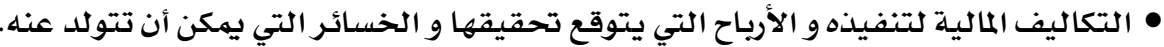

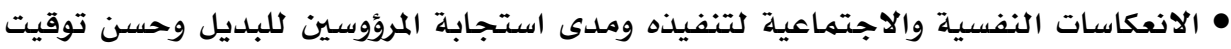
تنفيذه. • اختيار البديل الذي يؤدي إلى الاستغلال الأمثل لعناصر الإنتاج المادية و البشرية المتاحة بأقل 
• اختيار البديل الذي يضمن تحقيقه السرعة المطلوبة عندما يكون الحل ملما و عاجلا. وهكذا لكل بديل محاسنه ومساوئه، وعلى المدير أن يرى كل منها بالنسبة لكل بديل ويختار

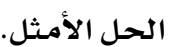
؟- اتخاذ القرار: ويتمثل يِّ اختيار أحد البدائل أو الحلول المطروحة ، والذي يرى متخذ القرار أنه أفضلها وأكثرها واقعية وقابلية للتنفيذا واتهئ.

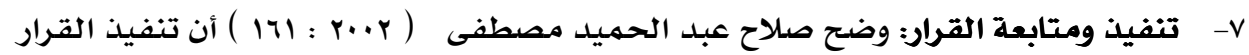

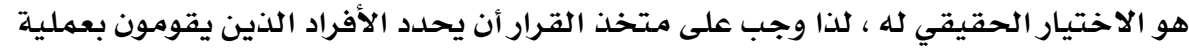

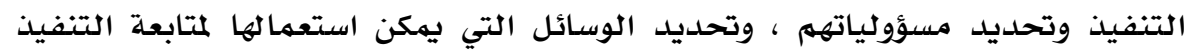

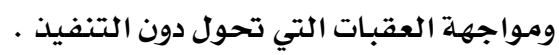

عناصر القرار:

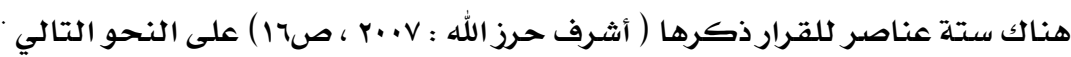

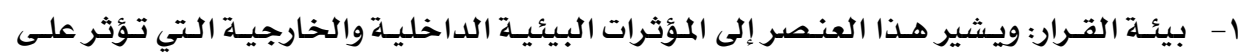
متخذذ القرار عند قيامه باختيار البديل الملائم.

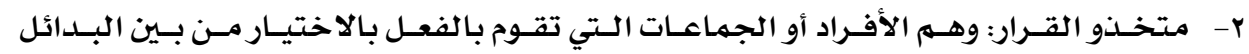

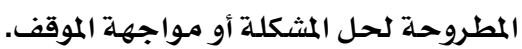

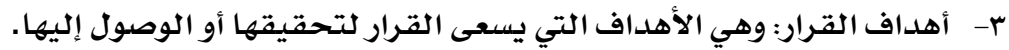

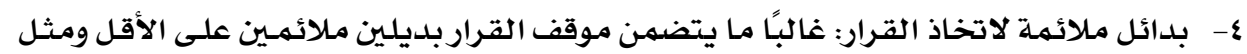

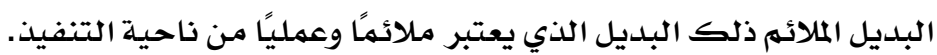

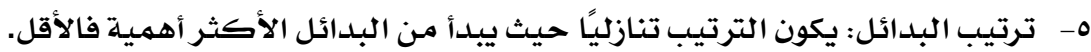

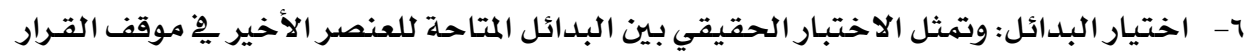

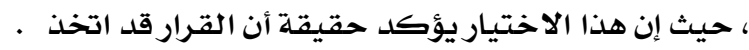

\section{ظروف صنع القرار}

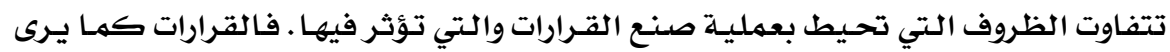

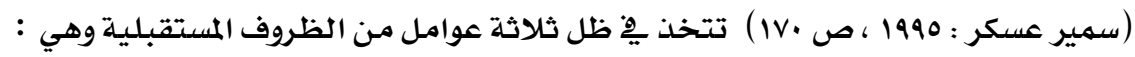
1- التأكد: تتوافر ظروف التأكد عندما يكون عند متخذ القرار معلومات كاملة عن النتائج

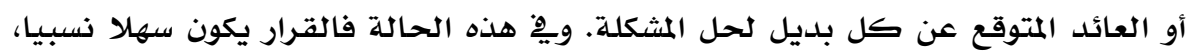

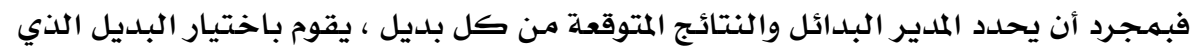

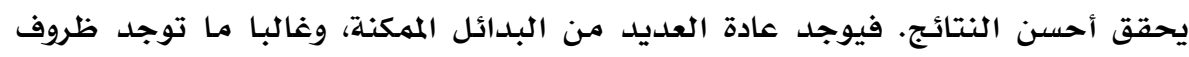

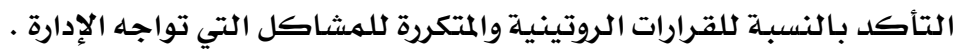

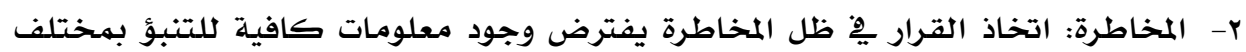

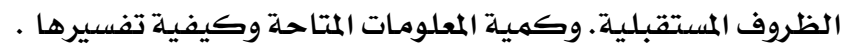




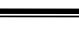
مجلة بحوث التربية النوعية - علد

r- ع عدم التأكد: تفترض ظروف عدم التأكد عدم وجود معلومات أو نفاذ البصيرة بالنسبة

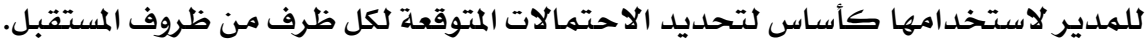

\section{الدراسات سابقة :}

دراسة نور جبار علي ( PV (Y) ) بعنوان " العنف الأسري وعلاقته بالسلوك العدواني لدى

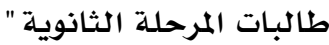

هدف البحث الحالي الى التعرف على العلاقة بين ممارسة العنف الأسري والسلوك

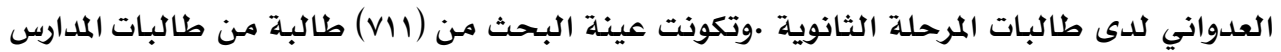

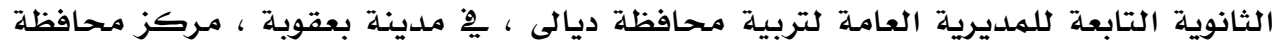

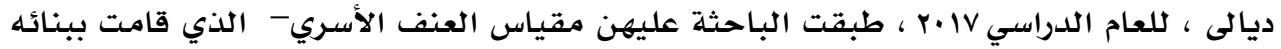

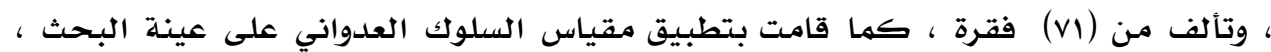

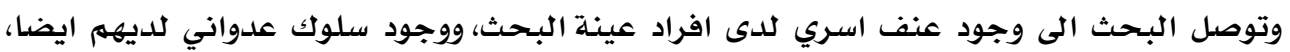

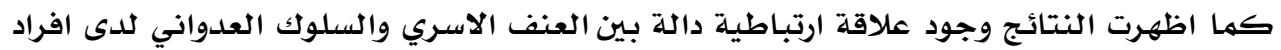
العينـة العها

دراسة عز الدين الخوالدة ، هناء خالد الرقاد (17 (r) : بعنوان مستويات التفكير الاخلاقي

وعلاقتها باتخاذ القرار لدى طلبة الجامعة الاردنية .

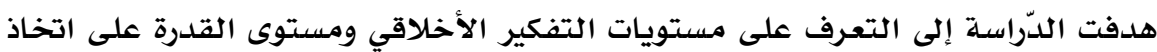

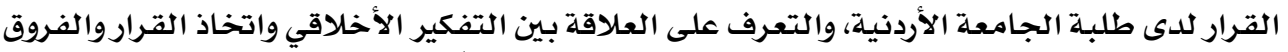
ذات الدلالة الإحصائية بين التفكير الأخلاقي واتخاذ القرار وفقا لمتغيرات الدراسة (الجنس، الدئه الكلية،

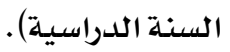

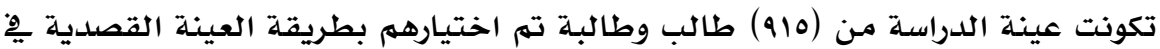

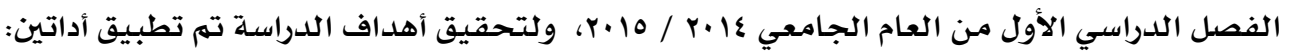

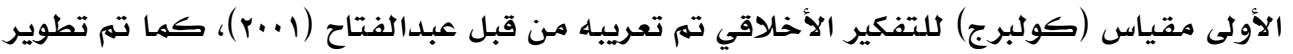

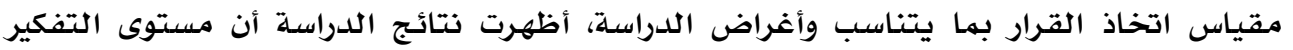

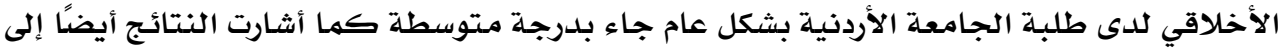

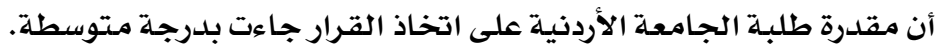

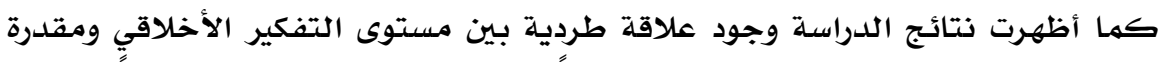

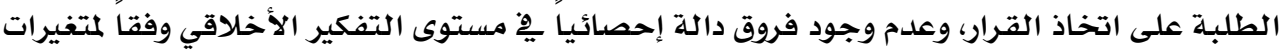

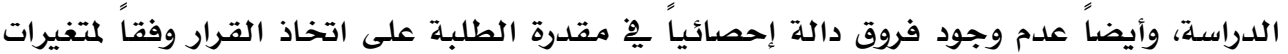
الدراسة.

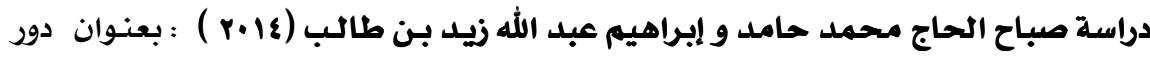

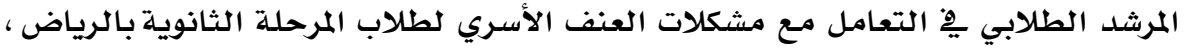




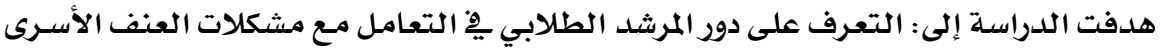

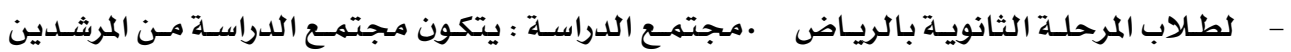

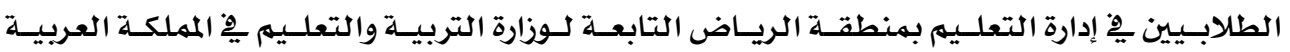

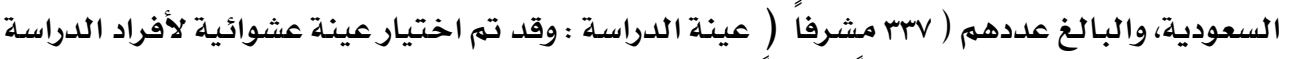

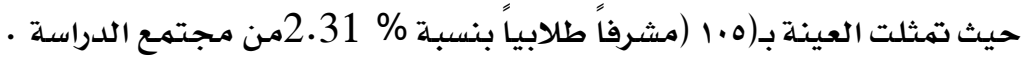

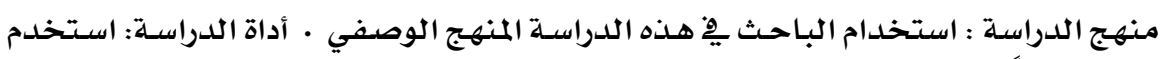

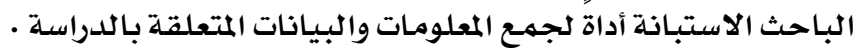
نتائج الدراسة:

$$
\text { توصلت الدراسة للنتائج الآتية }
$$

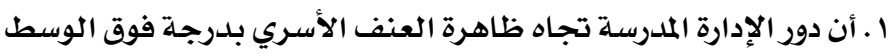

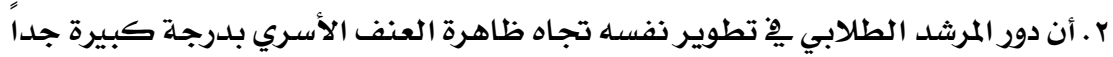

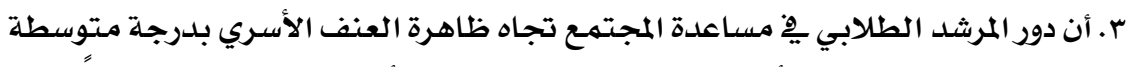

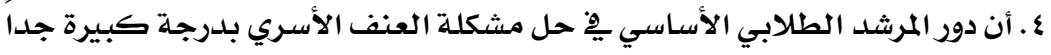

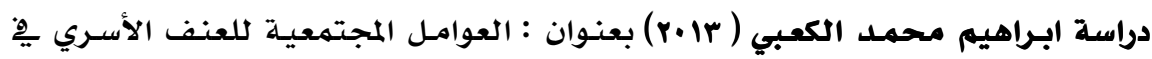
المجتمع القطري ابران

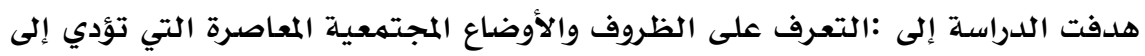

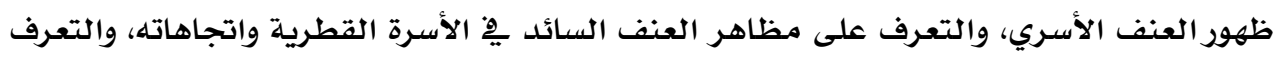

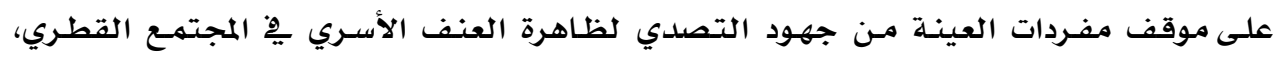

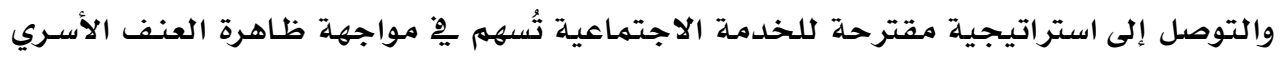
وعلاجها.

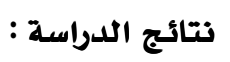

ا- تدخل الأهل والأقارب له الدور الأكبر ِِّ ظهور العنف الأسري المتمثل بالعنف بين

$$
\text { الزوج والزوجة. }
$$

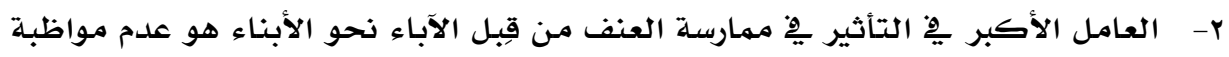

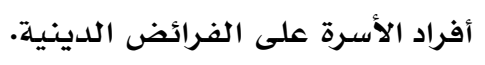

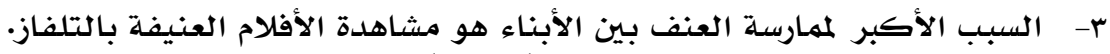

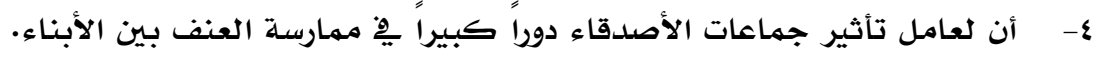

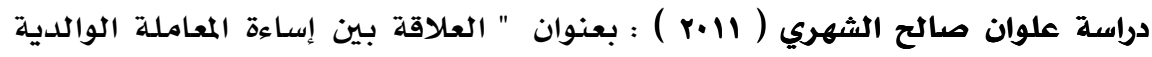

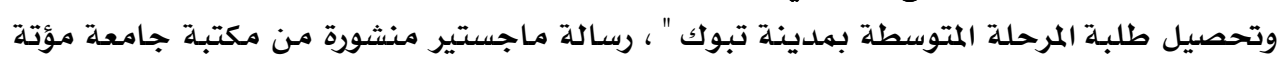

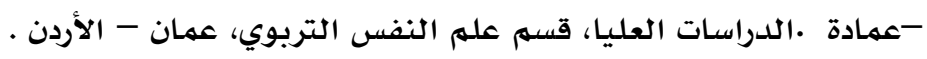




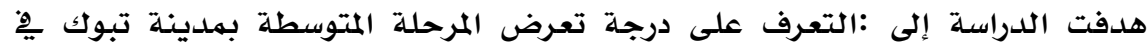

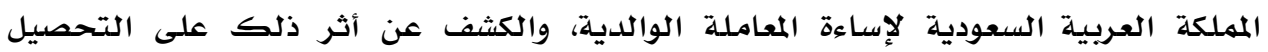
الأكاديهي لديهم.

نتائج الدراسة:

أن درجة تعرض المرحلة المتوسطة بمدينة تبوك فِ المملكة العربية السعودية لإساءة

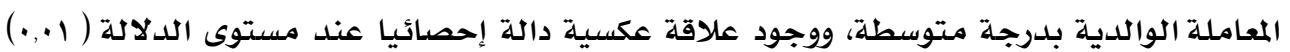

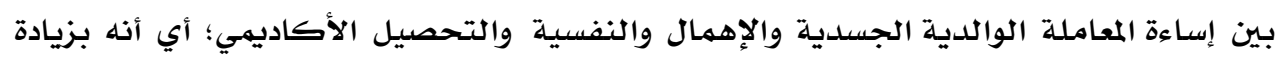

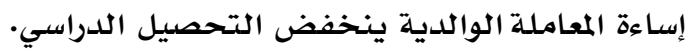

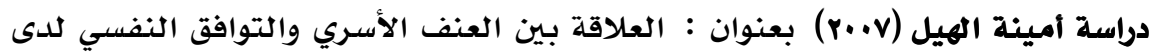

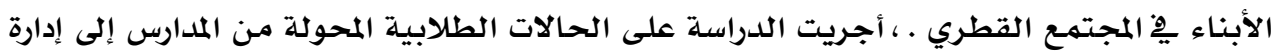

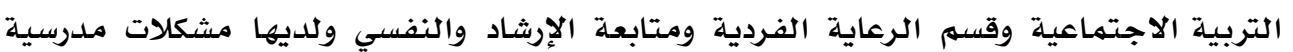
وظروف صعبة وتصدع أسري وتفكك بين العلاقات الأسرية. وقد هدفت الدراسة تعارف مظاهر العنف الأسري وعوامله والتوصل إلى التوصيات التي

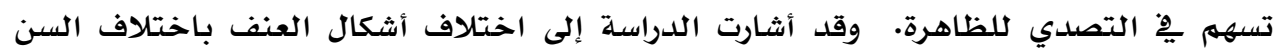

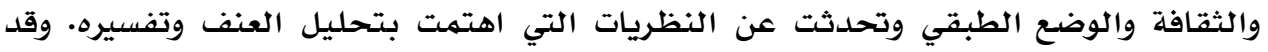

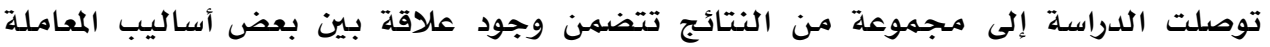

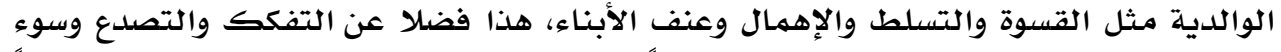

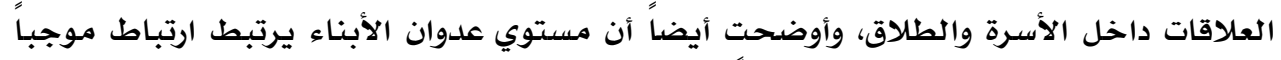

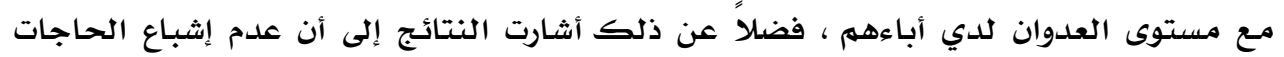

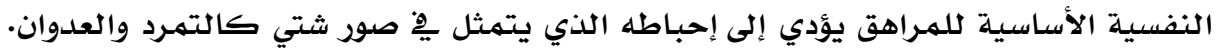

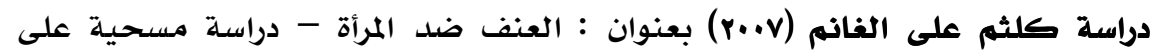

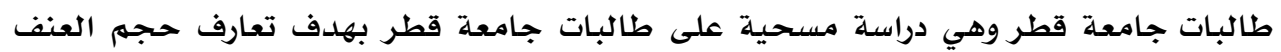

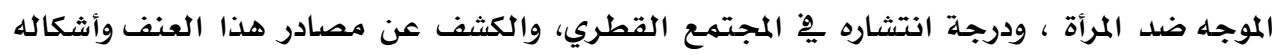

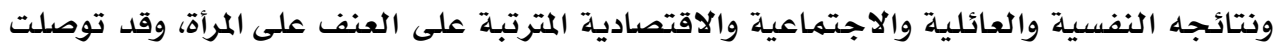

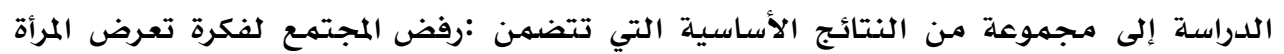

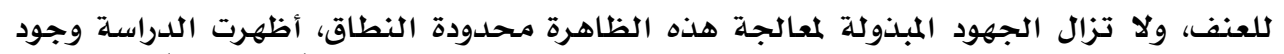

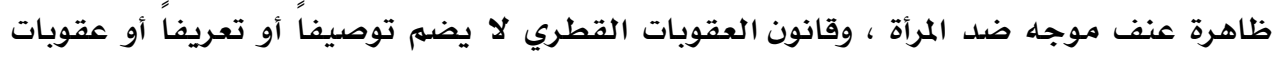

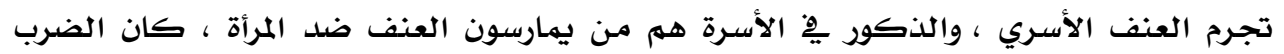

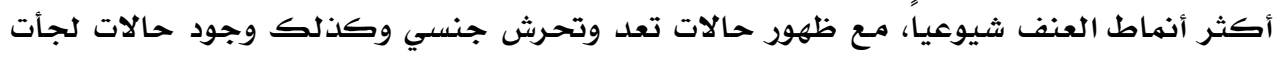

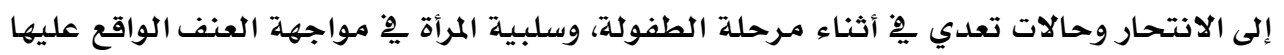

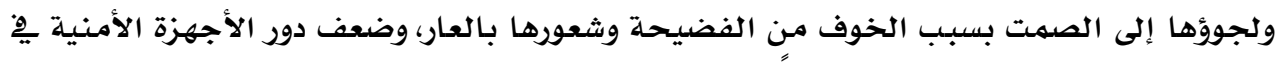

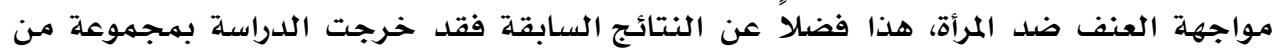


التوصيات تتضمن :توصيف جرائم العنف الأسري وإدراجها ضمن قانون العقوبات القطري،

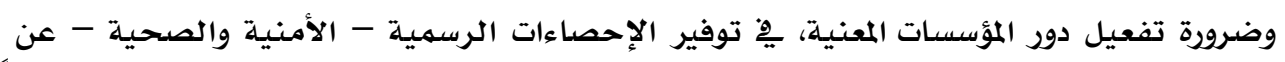

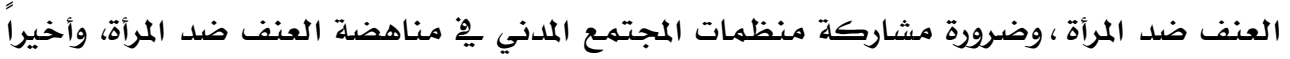

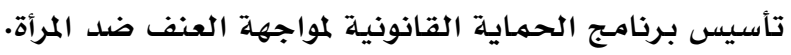

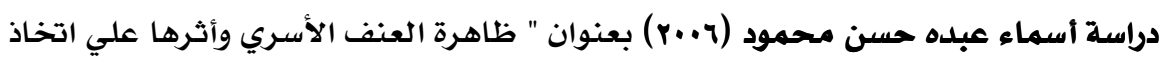

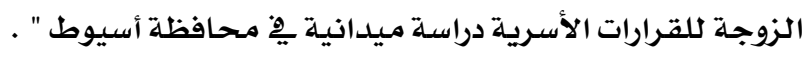

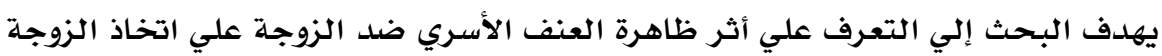
لبعض القرارات الأسريـة. وتتبلور مشكلة البحث يِّ الإجابة علي التساؤلات الآتية: ا ـ ما أثر ظاهرة العنف الأسري علي اتخاذ الزوجات للقرارات الأسريـة. r. ما هي أكثر العوامل تأثيراً علي العنف الأسري.

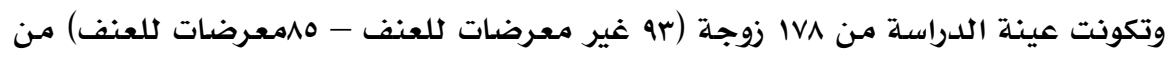

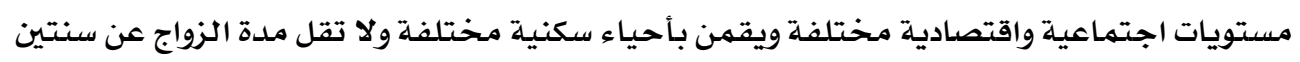

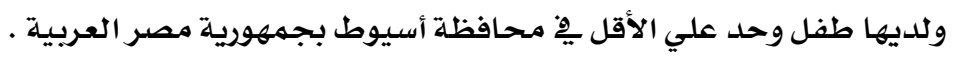
وأسفرت نتائج البحث علي ما يلي:

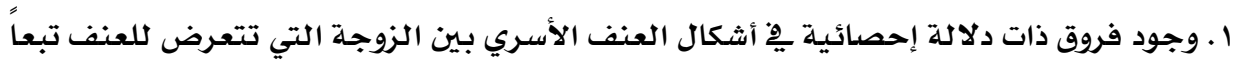

$$
\text { لبعض متغيرات الدراسـة. }
$$

r. توجد فروق ذات دلالة إحصائية بين الزوجة المعرضة للعنف ومثيلاتها غير المعرضدة يِّة مدي مساهمتها يِّ اتخاذ القرارات الأسريية.

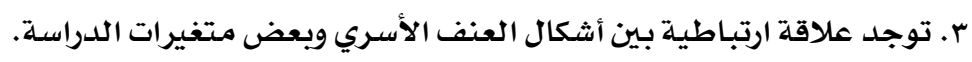

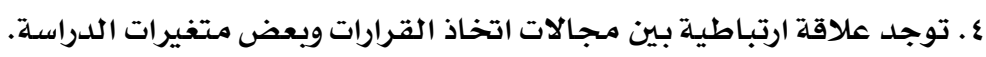

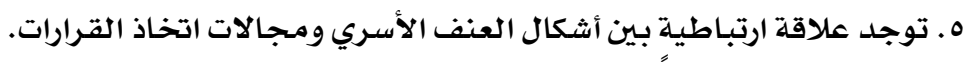

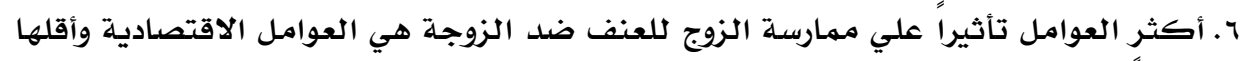
تأثيراً عامل المسكن. العوامل تاثيرا

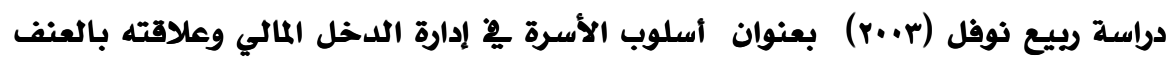

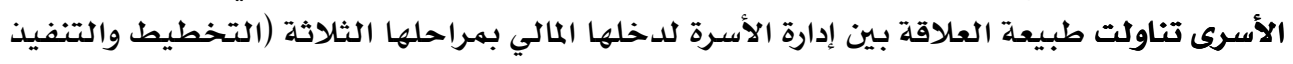

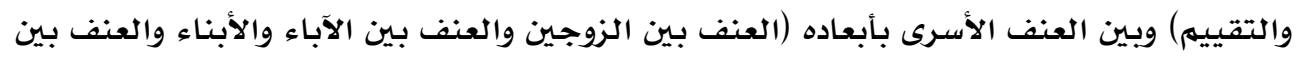

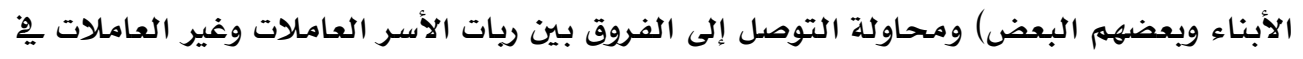

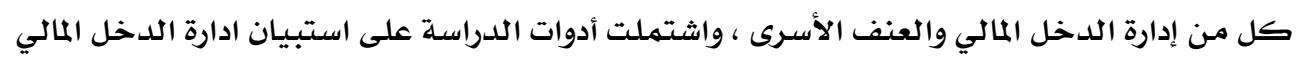

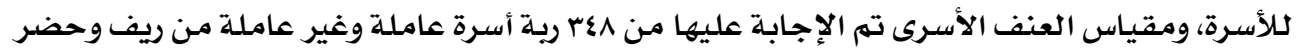

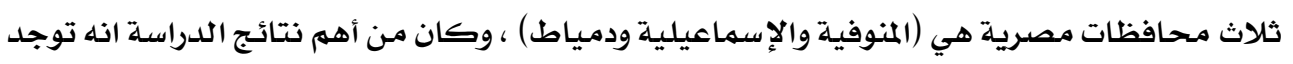


فروق دالة إحصائياً يِّ العنف الأسرى عند مستوى دلالة ه. • لصالح الحضريات، وتوجد اختلافات بين

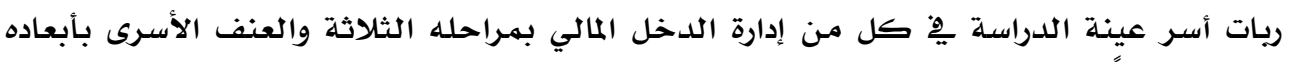

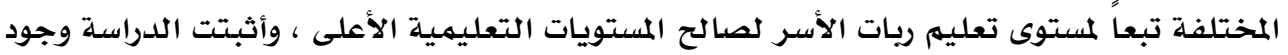

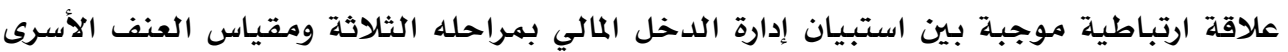

بأبعاده المختلفة.

دراسة وفاء فؤاد شلبى، فاطمة النبوية إبراهيم (1999) بعنوان " المناخ الأسرى وعلاقته

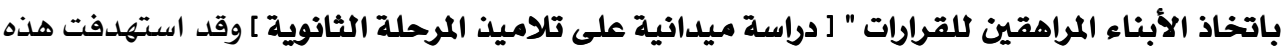

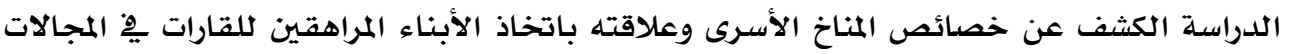

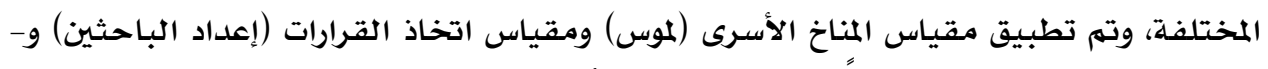

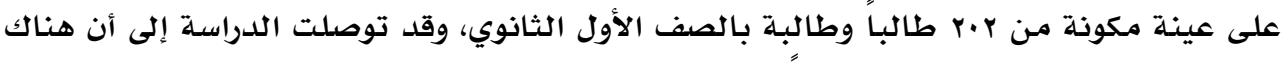

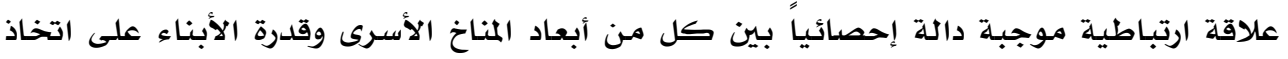

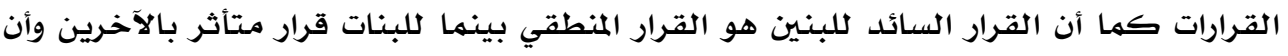

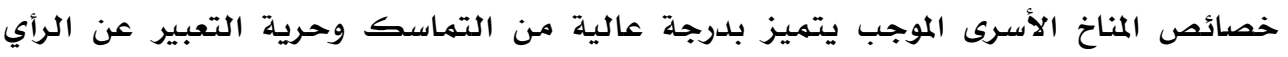
والاستقلال والتوجه نحو التحصيل والثقافة الافئ.

دراسة سميحة كرم (.199) بعنوان " أهم مشكلات الأسرة المصرية المرتبطة بإدارة المنزل "

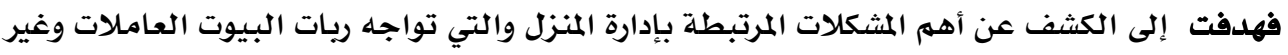

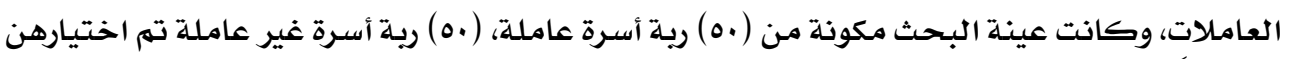

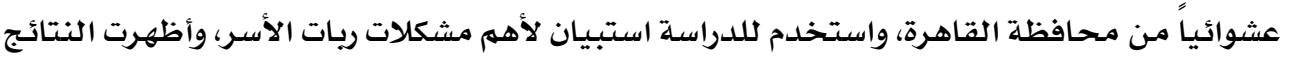

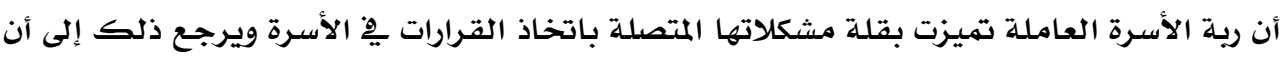

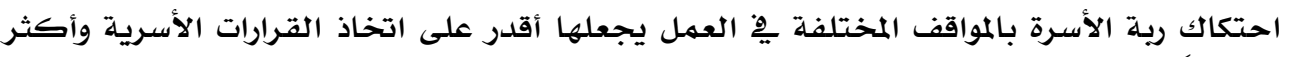

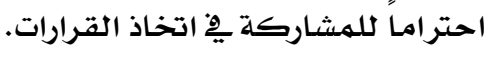

دراسة نجوى زكى (1919) بدراسة بعنوان " الإدراك المتبادل بين الآباء وأبنائهم المراهقين

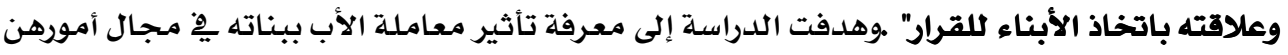

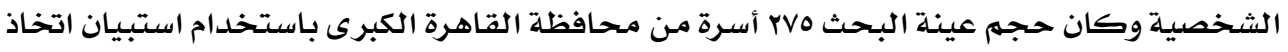
القرارات من إعداد الباحثة. ومن أهم نتائج الدراسة وجود ارتباط موجب دال إحصائياً بين اتجاه التسلط عند الأب وقرار التهور للابنة يْ مجال الأمور الشخصية. دراسة فتحية عبد الرؤوف على عوض (عی19 ) بعنوان "علاقة اتخاذ القرار ببعض متغيرات

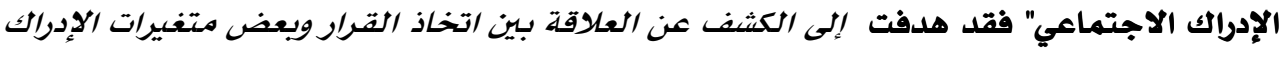

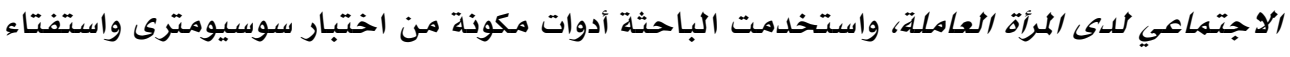

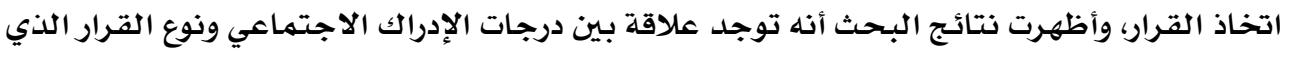

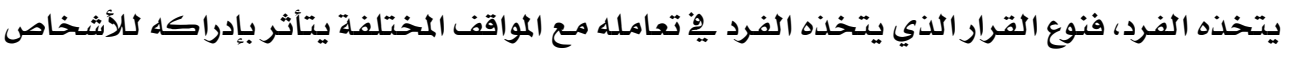


بناء على اتجاهه نحوهم سواء كان إيجابياً أو سلبياً ولذلك فإنه يهكن تغيير القرارات غير المرغوبة

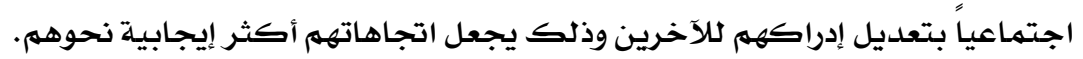

\section{نتائج الدراسة :}

\section{الفرض الأول:}

يوجد علاقة ارتباط عكسى ذات دلالة إحصائية بين العنف الأسري وعملية اتخاذ القرارات

وللتأكد من هذا الفرض قامت الباحثة بتطبيق معامل ارتباط بيرسون بين درجات استبيان

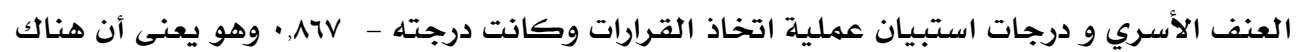

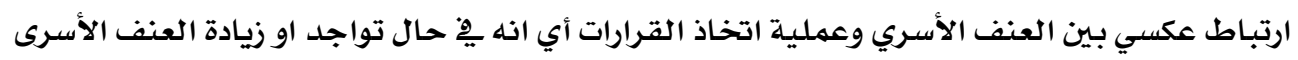

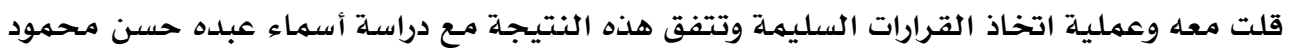

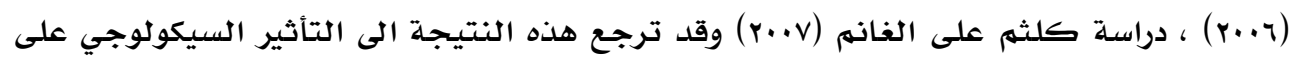

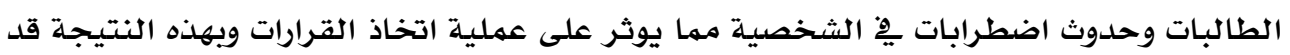
تحقق نتيجة الفرض الأول كلياً . الثرض الثاذي:

\section{هناك فروق ذات دلاكة إحصائية بين الطالبات الذين يعانون من العنف الأسرى والذين لا}

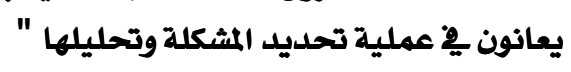
جدول (r) الفروق بين متوسط درجات الذين يعانون من العنف الأسرى والذين لا يعانون يـ عملية تحديد

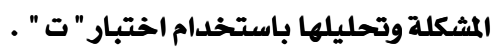

\begin{tabular}{|c|c|c|c|c|c|c|c|c|}
\hline 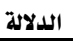 & |درجة الحرية & قيمة ت & معامل الخطأ & الانحراف المعيارى & التتوسط & العدد العد & \multicolumn{2}{|r|}{ تحديد المشكلة وتحليلها } \\
\hline \multirow{2}{*}{$\cdot, \cdots$} & \multirow{2}{*}{191} & \multirow{2}{*}{$7,1+1$} & $\cdot, \cdot 77$ & •, 1ะT & I, vr & 1.0 & لا يعانون من عنف أسري & \multirow{2}{*}{ تواجهني أحيانا بعض الصعوبات عند تحديل } \\
\hline & & & $\cdot, 04$ & •, or. & $r, r \cdot$ & 90 & يعانون من عنف أسري & \\
\hline \multirow{2}{*}{$\bullet, \cdots$} & \multirow{2}{*}{191} & \multirow{2}{*}{17,04} & $\cdot, .01$ & $\cdot, 0 . \cdot$ & $r, \$ 0$ & 1.0 & لا يعانون من عنف أسري & \multirow{2}{*}{ 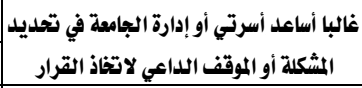 } \\
\hline & & & $\cdot, \bullet \xi V$ & •, ¿VV & $1, \pi \xi$ & 90 & يعانون من عنف أسري & \\
\hline \multirow{2}{*}{$\bullet, \cdots$} & \multirow{2}{*}{191} & \multirow{2}{*}{$\mathrm{rI}, \Delta \Lambda$. } &., 01 & $\cdot, \$ 90$ & $r, 09$ & 1.0 & لا يعانون من عنف أسري & \multirow{2}{*}{ اضطر أحيانا إلى اتخاذ قرارات دون تحديد } \\
\hline & & & $\cdot, \cdot \bullet$ & $\cdot, \xi \cdot 9$ & $1, r 1$ & 90 & يعانوز من عنف أسري & \\
\hline \multirow{2}{*}{$\bullet, \cdot 1 \varepsilon$} & \multirow{2}{*}{191} & \multirow{2}{*}{ r,\&AT } & $\cdot, \cdot v r$ & $\cdot, 799$ & 1,10 & 1.0 & لا يعانون من عنف أسري & \multirow{2}{*}{ أجد صعوبة عند تحري السبب الرئيسي لظهور } \\
\hline & & & $\cdot, \cdot v r$ & •, Vrr & $r, 1 \cdot$ & 90 & يعانون من عنف أسري & \\
\hline \multirow{2}{*}{$\cdot, \cdot 1$} & \multirow{2}{*}{191} & \multirow{2}{*}{$r, \Sigma 19$} & $\cdot, \cdot 77$ & $\cdot, 1 \leqslant 7$ & $1, \Lambda^{*}$ & 1.0 & لا يعانون من عنف أسري & \multirow{2}{*}{ لدي قلدرة محدودة على معرفة الوقت والمكان } \\
\hline & & & $\cdot, \cdot 7 v$ & $\cdot, 719$ & $r, i r$ & 90 & يعانون من عنف أسري & \\
\hline \multirow{2}{*}{ •, } & \multirow{2}{*}{191} & \multirow{2}{*}{$r, \wedge \leqslant 1$} & $\cdot, 197$ & $1,9 \cdot 7$ & $1 \cdot, \cdot 4$ & 1.0 & لا يعانون من عنف أسري & \multirow{2}{*}{ تحديد الشكلة وتحليلها } \\
\hline & & & $\cdot, \mathrm{Vrr}$ & I, YVY & $9, \pi r$ & 90 & يعانوز من عنف أسري & \\
\hline
\end{tabular}

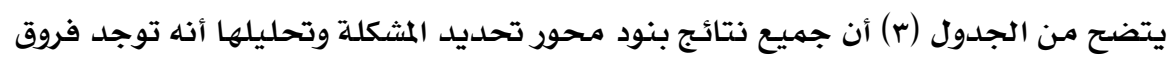

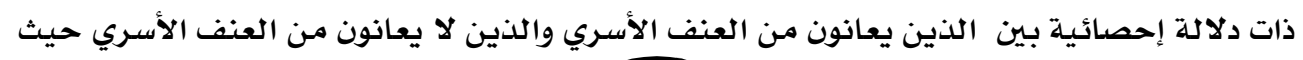


تكون النتيجة الايجابية الأعلى لصالح الذين لا يعانون من العنف الأسري ، وبالنسبة لأجمالي محور

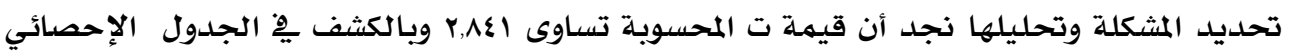

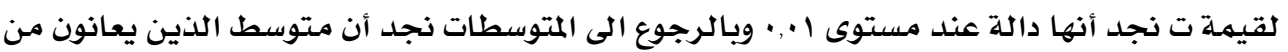

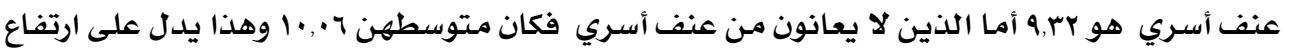

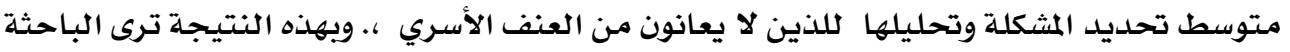

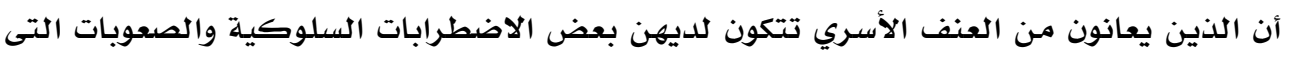
تواجِهِ

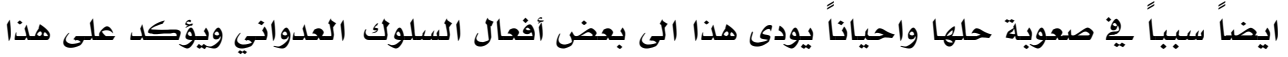

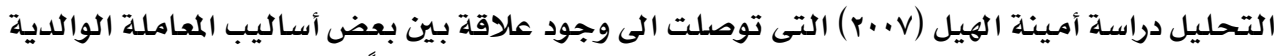

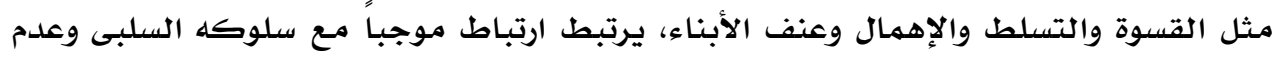

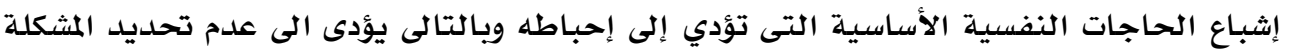

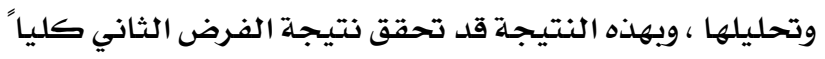

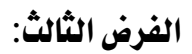

هناك فروق ذات دلالة إحصائية بين الطالبات الذين يعانون من العنف الأسرى والذين لا يعانون يْ عملية حصر البدائل .

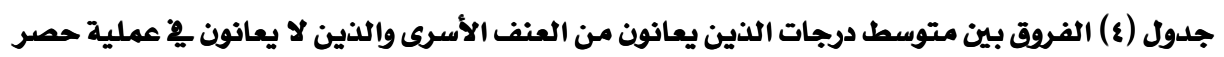

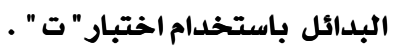

\begin{tabular}{|c|c|c|c|c|c|c|c|c|}
\hline الدلالة & |درجة الحرية & قيمة ت & معامل الخطأ & الانعراف المعيارى & | التتوسط & ا العدد & & حصر البدائل \\
\hline \multirow{2}{*}{$\cdot, \cdot r$} & \multirow{2}{*}{191} & \multirow{2}{*}{$r, \cdot / r$} & •, $+7 r$ & $\cdot, 0 \leqslant 0$ & $r, i v$ & 90 & لا يعانون من عنف أسري & \multirow{2}{*}{ أحيانا لا استطيع تحديد البدائل المككنة لمواجهة } \\
\hline & & & $\cdot, \cdot 04$ & $\cdot, 7 \cdot 7$ & 1,94 & 1.0 & | يعانون من عنف أسري & \\
\hline \multirow{2}{*}{$\cdot, \bullet 0$} & \multirow{2}{*}{191} & \multirow{2}{*}{ r,ATr } & $\cdot, \cdot 71$ & •, ova & $r, 1 \varepsilon$ & 90 & لا يعانون من عنف أسري & \multirow{2}{*}{ 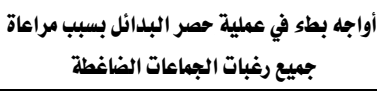 } \\
\hline & & & $\cdot, .07$ & $\cdot, 77$ & 1,19 & 1.0 & يعانون من عنف أسري & \\
\hline \multirow{2}{*}{ 年 } & \multirow{2}{*}{191} & \multirow{2}{*}{ r,ora } & $\cdot,+71$ & $\cdot, 011$ & $r, 1$ & 90 & لا يعانون من عنف أسري & \multirow{2}{*}{ 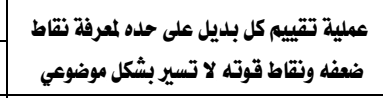 } \\
\hline & & & $\cdot, \cdot$ or & $\cdot, 099$ & $1, \wedge 1$ & 1.0 & ي يعانون من عنف أسري & \\
\hline \multirow{2}{*}{$\cdot, \cdot \& r$} & \multirow{2}{*}{191} & \multirow{2}{*}{$r, \&$ \& } & $\cdot, \cdot 7 \varepsilon$ & $\cdot, 0 \leqslant 7$ & $r, 1$ & 90 & لا يعانون من عنف أسري & \multirow{2}{*}{ تواجهني بعض صعوبات عند تحديد النتائج } \\
\hline & & & $\cdot, \cdot 0 \%$ & 每, & $1,9 r$ & 1.0 & يعانوز من عنف أسري & \\
\hline \multirow{2}{*}{$\cdot, \cdot \& r$} & \multirow{2}{*}{191} & \multirow{2}{*}{$r, \bullet \xi$} & $\cdot, \bullet \mathrm{Or}$ & $\cdot$, ory & $r, 1$ & 90 & لا يعانوز من عنف أسري & \multirow{2}{*}{ أحيانا لا تلبي البدائل المتوفرة متطلبات حل } \\
\hline & & & ., or & $\cdot, 00 \%$ & 1,90 & 1.0 & | يعانون من عنف أسري & \\
\hline \multirow{2}{*}{$\cdot, \cdot 1$} & \multirow[b]{2}{*}{191} & \multirow{2}{*}{ r, ¿r* } & $\cdot, \cdot v r$ & $\cdot, \mathrm{v} \cdot \xi$ & r, ro & 90 & لا يعانون من عنف أسري & \multirow{2}{*}{ أحيانا استعين بآراء الأصدقاء والزملاء لوضع التول التهل } \\
\hline & & & $\bullet, \cdot 79$ & •, Yol & 1,19 & 1.0 & ي يعانون من عنف أسري & \\
\hline \multirow{2}{*}{$\cdot, \cdot r$} & \multirow{2}{*}{191} & \multirow{2}{*}{$r, 99 r$} & $\cdot, \cdot \vee v 0$ & $\cdot, \mathrm{v}$. & $r, 19$ & 90 & لا يعانوز من عنف أسري & \multirow{2}{*}{ أقوم بالبحث عن حلول أخرى للمشكلة إذا لم } \\
\hline & & & $\cdot, \cdot \vee \varepsilon$ & $\cdot, \mathrm{vrr}$ & $I, \wedge r$ & 1.0 & يعانون من عنف أسري & \\
\hline \multirow[b]{2}{*}{$\bullet, \cdots$} & \multirow[b]{2}{*}{191} & \multirow[b]{2}{*}{$0, \cdot 1 \cdot$} & •, & $r, \cdots r$ & $10, r r$ & 90 & لا يعانون من عنف أسري & \multirow{2}{*}{ حصر البدائل } \\
\hline & & & • & r, riv & $1 r, 91$ & 1.0 & | يعانون من عنف أسري & \\
\hline
\end{tabular}


يتضح من الجدول (ع) أن جميع نتائج بنود محور حصر البدائل أنه توجد فروق ذات دلالة التئ

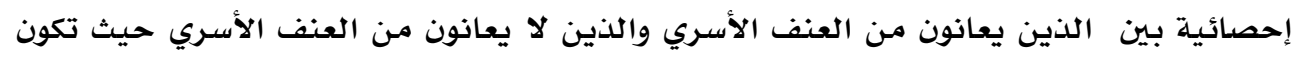

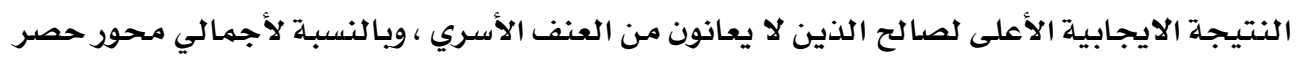

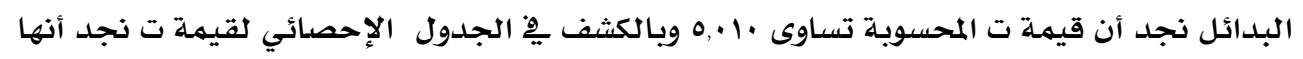

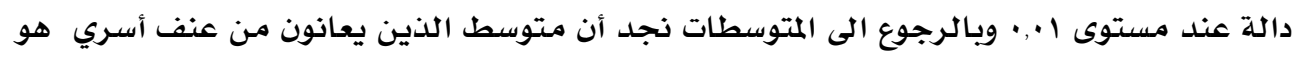

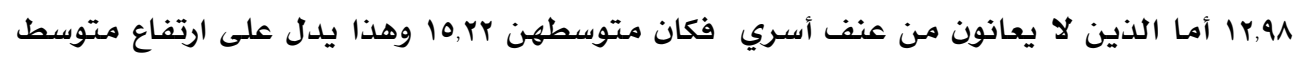

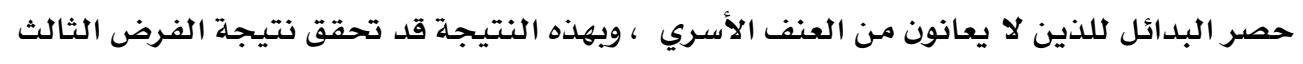

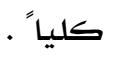

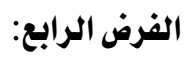

هناك فروق ذات دلالة إحصائية بين الطالبات الذين يعانون من العنف الأسرى والذين لا يعانون ف2 عملية تقييم البدائل ". جدول (ه) الفروق بين متوسط درجات الذين يعانون من العنف الأسرى والذين لا يعانون يِ عملية تقييم البدائل باستخدام اختبار " ت " . ل

\begin{tabular}{|c|c|c|c|c|c|c|c|c|}
\hline الدلالة & |درجة الحرية & قيمة ت & معامل الخطأ & الانحراف المعيارى & المتوسط & 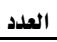 & & تقييم البلدائل \\
\hline \multirow{2}{*}{$\cdot, \cdot \bullet r$} & \multirow{2}{*}{191} & \multirow{2}{*}{$r, \cdot 9 r$} & $\cdot, \cdot 71$ & $\cdot, 791$ & $r, 11$ & 90 & لا يعانون من عنف أسري & \multirow{2}{*}{ أضخع معايير تقويم الحلول المطروحة للمشكلة المراد } \\
\hline & & & $\cdot, \cdot v_{1}$ & $\cdot, 719$ & 1,11 & 1.0 & يعانوز من عنف أسري & \\
\hline \multirow{2}{*}{$\cdot, \cdot r$} & \multirow{2}{*}{191} & \multirow{2}{*}{$r, \cdot r$} & $\cdot, .99$ & $\cdot, \mathrm{v}: \varepsilon$ & $r, 10$ & 90 & لا يعانون من عنف أسري & \multirow{2}{*}{ أقوم بعملية المفاضلة بين البدائل المتاحة واختيار } \\
\hline & & & $\cdot, \cdot v r$ & $\cdot, \mathrm{V} \leqslant \Lambda$ & $1, \wedge \varepsilon$ & 1.0 & يعانوز من عنف أسري & \\
\hline \multirow{2}{*}{$\cdot, \cdot \bullet r$} & \multirow{2}{*}{191} & \multirow{2}{*}{$r, 1 . \varepsilon$} & $\cdot, \cdot 79$ & $\cdot, 711$ & $r, 17$ & 90 & لا يعانون من عنف أسري & \multirow{2}{*}{ استطيع تحديلد الوقت المناسب والظروف الملائمة } \\
\hline & & & $\cdot, \cdot v$ & •, TrA & 1,17 & 1.0 & يعانوز من عنف أسري & \\
\hline \multirow{2}{*}{$\cdot, \cdots 1$} & \multirow{2}{*}{191} & \multirow{2}{*}{ 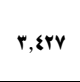 } & $\cdot, \cdot V r$ & $\cdot, \mathrm{v} \varepsilon$ & $r, I V$ & 90 & لا يعانون من عنف أسري & \multirow{2}{*}{ أحيانا استفيد من خبرات الآخرين في تحديد } \\
\hline & & & $\cdot, \cdot v r$ & $\cdot, \mathrm{V} \leqslant A$ & $1, \wedge 1$ & 1.0 & يعانوز من عنف أسري & \\
\hline \multirow{2}{*}{$\bullet, \cdot \bullet 1$} & \multirow{2}{*}{191} & \multirow{2}{*}{ r,orv } & $\cdot, \cdot 0 r$ & $\cdot, 0 \leqslant \xi$ & $r, r$ & 90 & لا يعانون من عنف أسري & \multirow{2}{*}{ أقوم بالتعرف على ملدى استجابة أولياء الأمور } \\
\hline & & & $\cdot, \cdot 70$ & •, Trv & 1,91 & 1.0 & يعانوز من عنف أسري & \\
\hline \multirow{2}{*}{$\cdot, \cdots$} & \multirow{2}{*}{191} & \multirow{2}{*}{$\xi, 7 \vee \varepsilon$} & •,rv乏 & $r, A \cdot 0$ & $1 \cdot, 9 r$ & 90 & لا يعانون من عنف أسري & \multirow{2}{*}{ تقيييم البلدائل } \\
\hline & & & $\cdot, r \cdot q$ & $r, \cdot 1 r$ & $9, \cdot 1$ & 1.0 & يعانوز من عنف أسري & \\
\hline
\end{tabular}

يتضح من الجدول (ه) أن جميع نتائج بنود محور تقييم البدائل أنه توجد فروق ذات دلالة

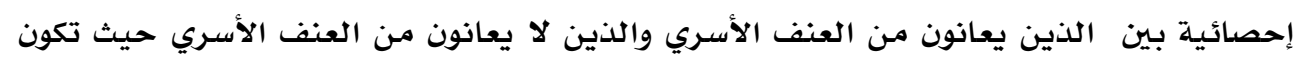

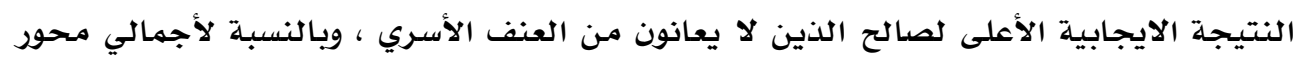

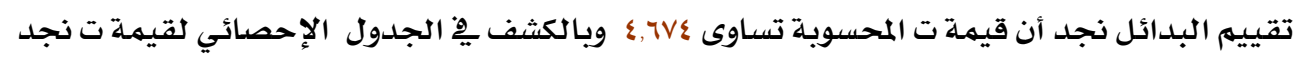

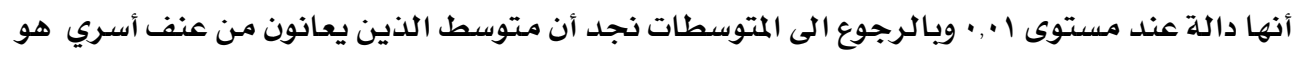

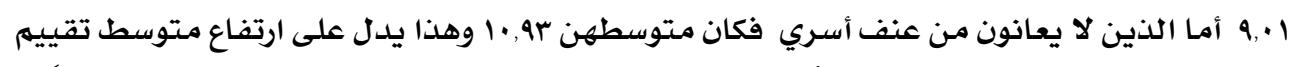

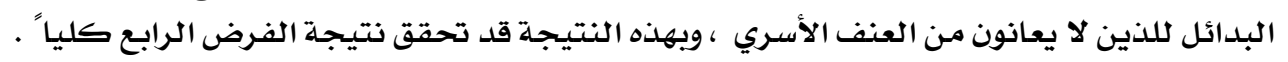


هناك فروق ذات دلالة إحصائية بين الطالبات الذين يعانون من العنف الأسرى والذين لا

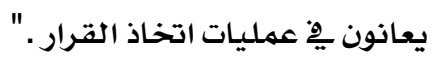

جدول (7) الفروق بين متوسط درجات الذين يعانون من العنف الأسرى والذين لا يعانون يُ محور اتخاذ القرار

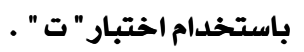

\begin{tabular}{|c|c|c|c|c|c|c|c|c|}
\hline 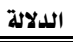 & |درجة الحرية & 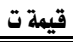 & معامل الخطأ & الانعراف المعيارى & | المتوسط & | العدد & & اتخاذ القرار \\
\hline \multirow{2}{*}{$\cdot, \cdot+\Lambda$} & \multirow{2}{*}{191} & \multirow{2}{*}{$r, \bullet \wedge$} & $\cdot \cdot \cdot \bullet r$ & $\cdot, \xi r \wedge$ & $r, 1$ & 90 & لا يعانون من عنف أسري & \multirow{2}{*}{ تواجهني بعض الصعوبات تعيق اتخاذ قرارات } \\
\hline & & & $\cdot, \cdot$ or & $\cdot, 0 . \xi$ & 1,97 & 1.0 & يعانون من عنف أسري & \\
\hline \multirow{2}{*}{$\bullet, \cdots 9$} & \multirow{2}{*}{191} & \multirow{2}{*}{$r, T \leqslant Y$} & $\cdot, \cdot 0$ & $\cdot, 01$ & $r, 1$ & 90 & لا يعانون من عنف أسري & \multirow{2}{*}{ هناك العديل من القرارات في حياتي التي يته } \\
\hline & & & $\cdot, \cdot 7 r$ & $\cdot, 717$ & $1,1 \wedge$ & 1.0 & يعانون من عنف أسري & \\
\hline \multirow{2}{*}{$\bullet, \cdot \bullet$} & \multirow{2}{*}{191} & \multirow{2}{*}{ r, १7r } & •, • & •, $7 \leqslant$ r & $r, I V$ & 90 & لا يعانون من عنف أسري & \multirow{2}{*}{ أحيانا اشعر باللامبالاة عند اتخاذ القرارات } \\
\hline & & & $\bullet, \bullet 79$ & $\cdot, 7 \vee 4$ & 1,19 & 1.0 & يعانون من عنف أسري & \\
\hline \multirow{2}{*}{$\cdot, \cdot \cdot 1$} & \multirow{2}{*}{191} & \multirow{2}{*}{$r, r r Y$} & $\bullet, \bullet r 1$ & •, YrV & $r, I V$ & 90 & لا يعانون من عنف أسري & \multirow{2}{*}{ مساعدة الأهل على اتخاذ القرار المناسب في } \\
\hline & & & $\cdot, \cdot \Delta r$ & $\cdot, \Lambda \cdot r$ & $1, \wedge 1$ & 1.0 & يعانون من عنف أسري & \\
\hline \multirow{2}{*}{$\cdot, \cdot r$} & \multirow{2}{*}{191} & \multirow{2}{*}{$r, r \mid$. } & $\cdot, \cdot 01$ & $\cdot, 0 \wedge 9$ & r, Ir & 90 & لا يعانون من عنف أسري & \multirow{2}{*}{ غالبا استخدم الأساليب الكمية ـ كتعدد البدائل } \\
\hline & & & $\cdot, .07$ & $\cdot, 00$ & $1, \wedge r$ & 1.0 & يعانون من عنف أسري & \\
\hline \multirow{2}{*}{$\cdot, \bullet \xi$} & \multirow{2}{*}{191} & \multirow{2}{*}{ r,AYr } & $\cdot, \cdot 70$ & $\cdot, 74 \mathrm{~V}$ & $r, 17$ & 90 & لا يعانون من عنف أسري & \multirow{2}{*}{ اعمل على تحقيق الأهداف المرجوة بأكبر قدر . } \\
\hline & & & $\cdot, \cdot V r$ & •, 7av & $1, \wedge \wedge$ & 1.0 & يعانون من عنف أسري & \\
\hline \multirow{2}{*}{$\bullet, \cdot \bullet$} & \multirow{2}{*}{191} & \multirow{2}{*}{ r, Trt } & $\cdot, .07$ & •, OVF & $r, I r$ & 90 & لا يعانون من عنف أسري & \multirow{2}{*}{ تواجهني مشكلات تتعلق بالتسلسل التنظيمي } \\
\hline & & & $\cdot, \cdot 71$ & $\cdot, 090$ & $1,9 r$ & 1.0 & يعانون من عنف أسري & \\
\hline \multirow{2}{*}{$\cdot, \cdot 10$} & \multirow{2}{*}{191} & \multirow{2}{*}{ r, \&OA } & $\cdot, .00$ & $\cdot, 07 \mathrm{~V}$ & $r, I r$ & 90 & لا يعانون من عنف أسري & \multirow{2}{*}{ أجد صعوبة عند تحديد الطريقة الصحيحة } \\
\hline & & & $\cdot, \cdot 90$ & r & $1,9 \mathrm{r}$ & 1.0 & يعانون من عنف أسري & \\
\hline \multirow{2}{*}{$\bullet, \cdots$} & \multirow{2}{*}{191} & \multirow{2}{*}{$\varepsilon, \Gamma \wedge 1$} & $\cdot, r \leqslant q$ & $r$, OYY & iv,r & 90 & لا يعانون من عنف أسري & \\
\hline & & & $\cdot$, \& & $\varepsilon, 1 v$ & $1 \xi, \wedge q$ & 1.0 & يعانون من عنف أسري & الهتاد الهرار \\
\hline
\end{tabular}

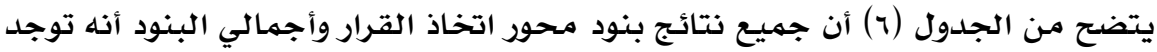

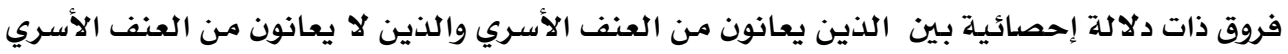

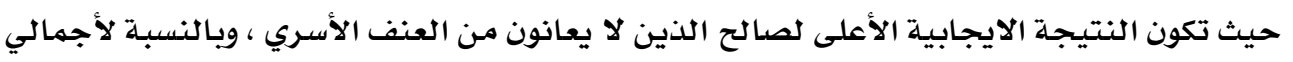

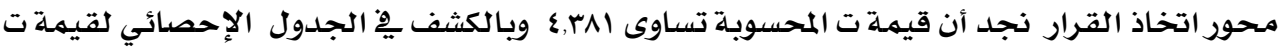

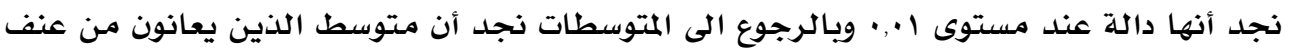

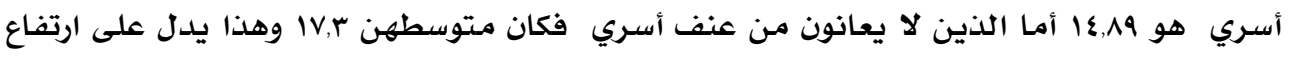

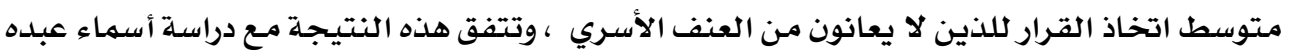

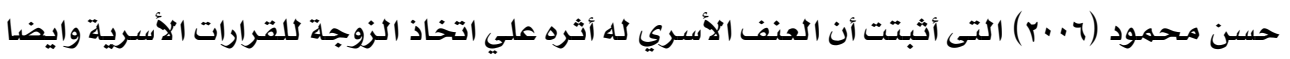

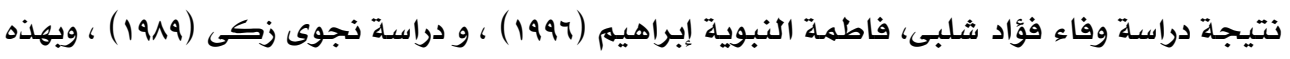

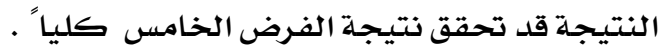


1. ضرورة متابعة الدولة لما يتم عرضه يِّ وسائل الأعلام والتأكد من خلوها من مشاهد العنف

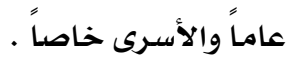

r. تفعيل ندوات داخل الهيئات الحكومية وغير الحكومية لتعزيز الثقافة الاجتماعية الناهية عن الاهن

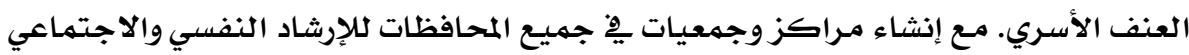

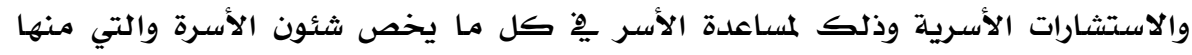
كيفية طرق منع إساءة المعاملة والوقاية منها.

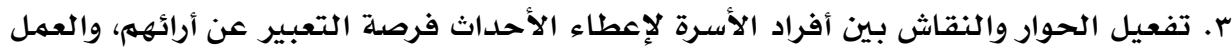
على تلبية احتياجاتهم المادية والنفسية.

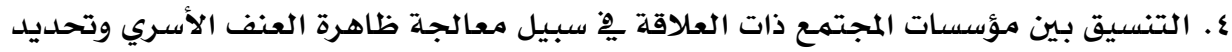
والأسباب وطرق المعالجة. المراجع : ا. ابراهيم محمد الكعبي ( rا •r) : العوامل المجتمعية للعنف الأسري يِّ المجتمع القطري ، مجلة جامعة

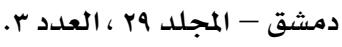

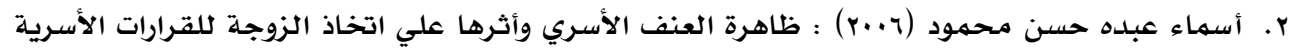

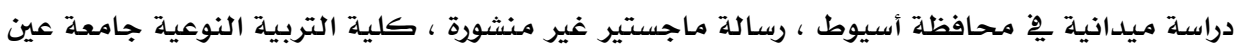
شمس . ش

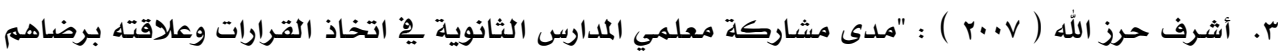

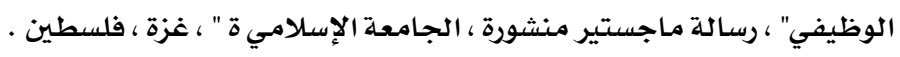

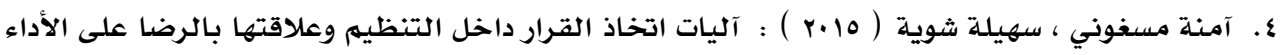

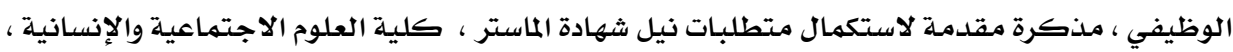

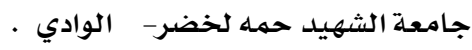

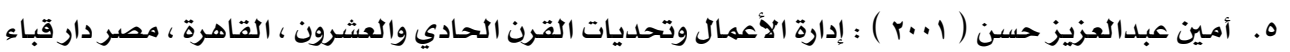

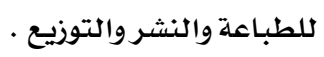

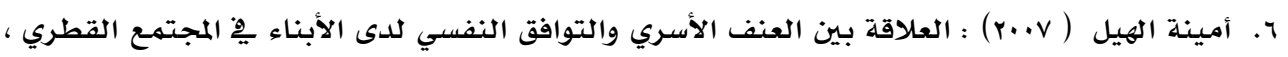

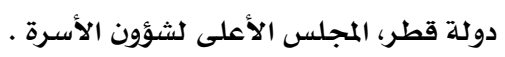

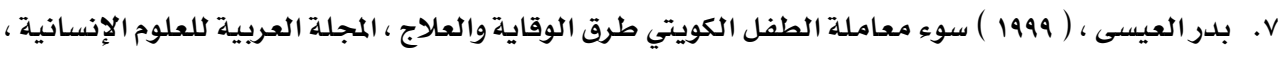

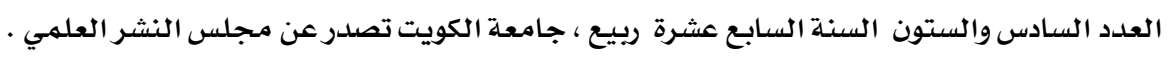

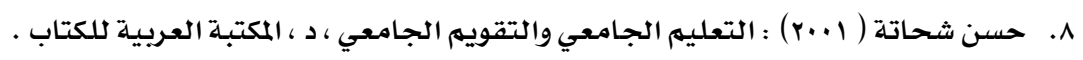

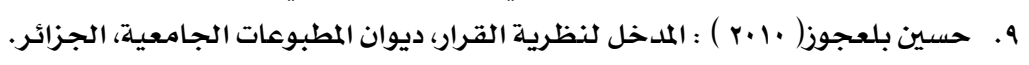

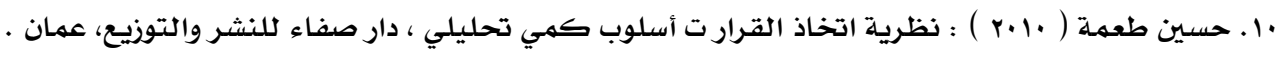

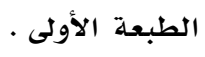




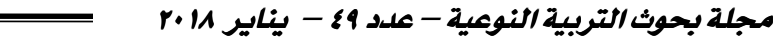

ال. حمدي الفرماوي، و وليد حسن(ع...r) : الميتامعرفية بين النظرية والبحث، مكتبة الأنجلو المصرية،

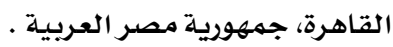

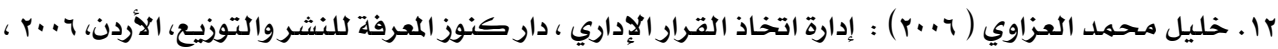

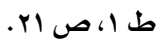

rا. ذياب البداينة (...r) : سوء معاملة الأطفال: الضحية المنسية، مجلة الفكر الشرطي، م(11)، ع (11)، المملكة العربية السعودية.

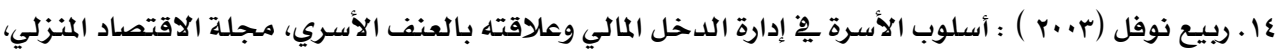

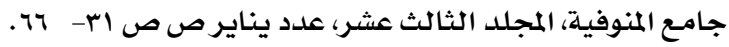

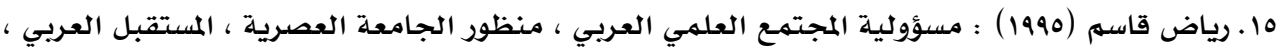
العدد بها 19 ، الكويت.

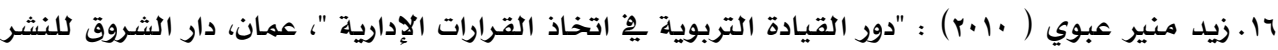
والتوزيع · مين

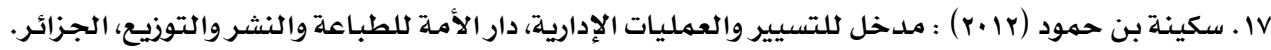

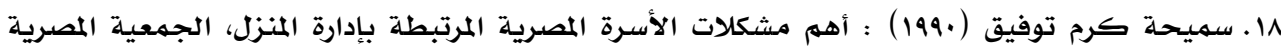

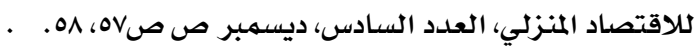

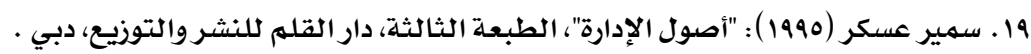

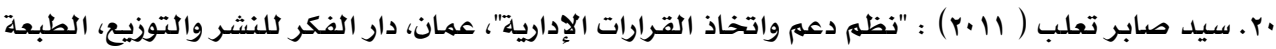

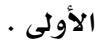

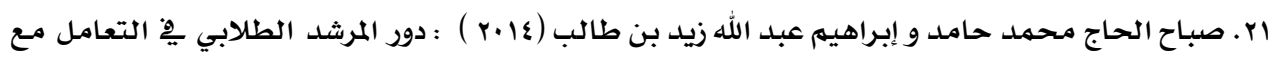

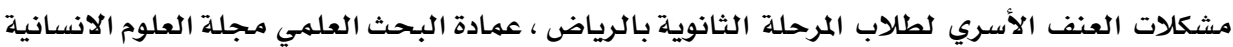

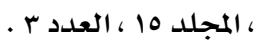

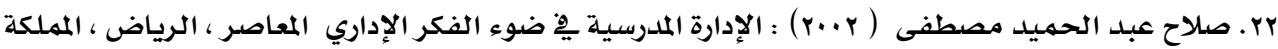

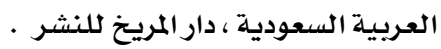

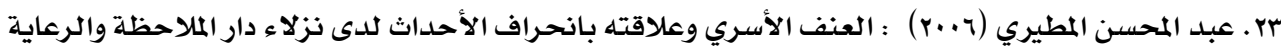

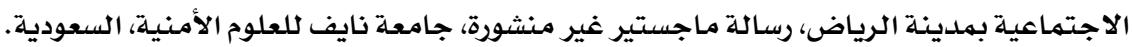

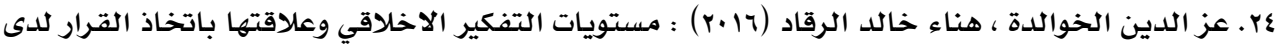

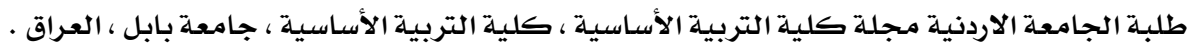

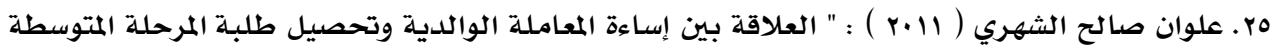

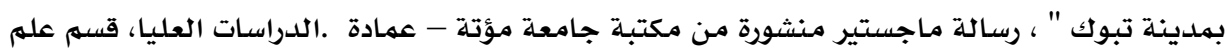

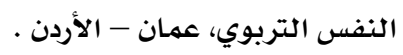

ب. . غريب إبراهيم (1991) : التغير الاجتماعي وأثره علي سلطة اتخاذ القرار داخل الأسرة، رسالة ماجستير غير الأني منشورة، قسم اجتماع، كلية الآداب، جامعة الزقازيق. 
VV.r. فتحية عبد الرؤوف علي (£\19) : علاقة اتخاذ الفرد للقرار ببعض متغيرات لإدراك الاجتماعي، رسالة

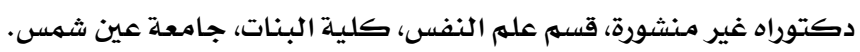

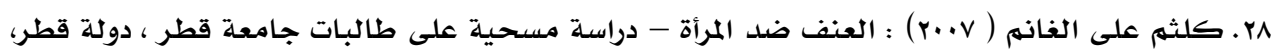

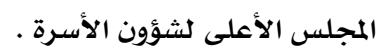

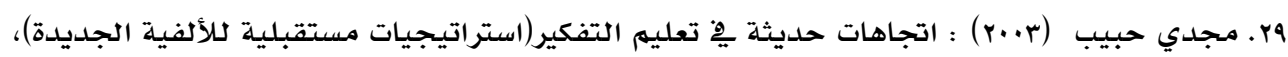

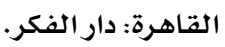

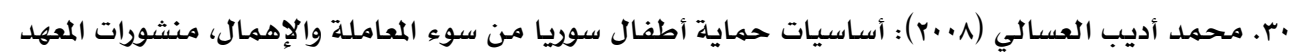

$$
\text { متوسط العالي للبحوث السكانية، دمشق. }
$$

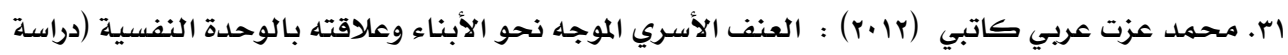

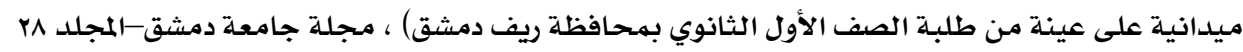

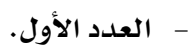

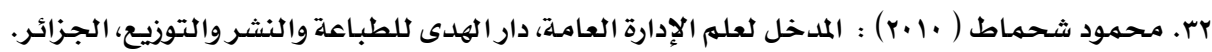

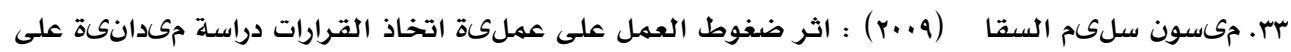

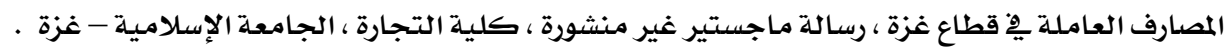

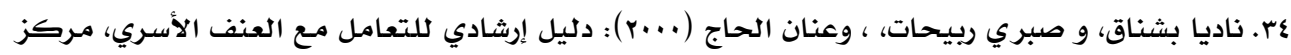
التوعية والإرشاد الأسري، الزرقاء، الأردن.

هr. نجوى زكي (1919) : الإدراك المتبادل بين الآباء وأبنائهم المراهقين وعلاقته باتخاذ الأبناء للقرارات، رسالة دكتوراه غير منشورة، كلية البنات، جامعة عين شمس.

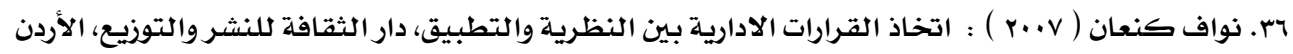
، طا. Vr. نواف كنعان (r..r ) ) : "اتخاذ القرارات الإدارية بين ال نظرية والتطبيق "، عمان ، دار الثقافة للنشر

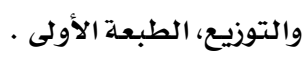

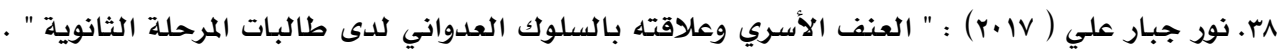

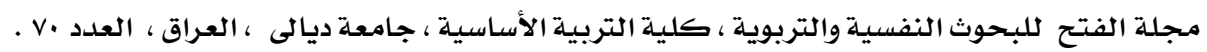

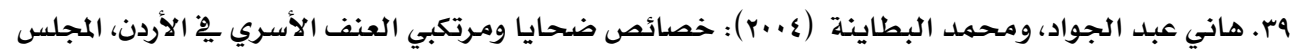
الأعلى للعلوم والتكنولوجيا، عمان، الأردن.

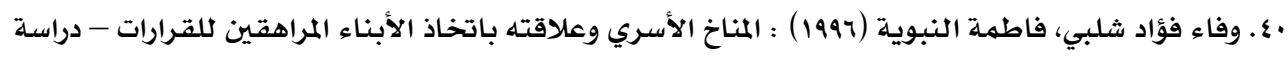

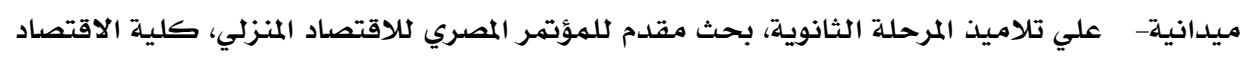

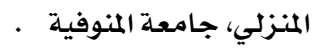

41.Berry, D. B. (1995) The Domestic violence: Source book everything you need to know (3rd). Lowell House, NTc, contem Porary Publishing Group, Inc, Los Angeles, U.S.A. . 
مجلة بحوث التربية النوعية - علد

42.Brown, J.E. and Mann, L., (1990): The relationship between family structure, process variables and decision making, Journal of adolescence, Vol. 13 P.P. 2537.

43.FEMA's Independent Study Program, "Decision Making and Problem Solving", South Seton Avenue, 2010 .

44.Garbarino, J. (1980): 'Future directions', in R.T. Ammerman and M. Hersen (eds), Children at Risk: An Evaluation of Factors Contributing to Child Abuse and Neglect, Plenum Press, New York. . 